\title{
8-2014
}

\section{Merger Negotiations with Stock Market Feedback}

\author{
Sandra Betton \\ B. Espen Eckbo \\ Rex Thompson \\ Karin S. Thorburn \\ University of Pennsylvania
}

Follow this and additional works at: https://repository.upenn.edu/fnce_papers

Part of the Finance Commons, and the Finance and Financial Management Commons

\section{Recommended Citation}

Betton, S., Eckbo, B. E., Thompson, R., \& Thorburn, K. S. (2014). Merger Negotiations with Stock Market Feedback. The Journal of Finance, 69 (4), 1705-1745. http://dx.doi.org/10.1111/jofi.12151

Author Karin S. Thorburn is a full time faculty member of Norwegian School of Economics. She is a visiting professor in the Finance Department of the Wharton School at the University of Pennsylvania.

This paper is posted at ScholarlyCommons. https://repository.upenn.edu/fnce_papers/180

For more information, please contact repository@pobox.upenn.edu. 


\title{
Merger Negotiations with Stock Market Feedback
}

\begin{abstract}
Do preoffer target stock price runups increase bidder takeover costs? We present model-based tests of this issue assuming runups are caused by signals that inform investors about potential takeover synergies. Rational deal anticipation implies a relation between target runups and markups (offer value minus runup) that is greater than minus one-for-one and inherently nonlinear. If merger negotiations force bidders to raise the offer with the runup-a costly feedback loop where bidders pay twice for anticipated target synergies-markups become strictly increasing in runups. Large-sample tests support rational deal anticipation in runups while rejecting the costly feedback loop.

Disciplines

Finance | Finance and Financial Management

\section{Comments}

Author Karin S. Thorburn is a full time faculty member of Norwegian School of Economics. She is a visiting professor in the Finance Department of the Wharton School at the University of Pennsylvania.
\end{abstract}




\section{ecgi}

\section{Merger negotiations with stock market feedback}

Finance Working Paper N 392/2013

November 2013
Sandra Betton

John Molson School of Business, Concordia University

B. Espen Eckbo

Tuck School of Business at Dartmouth

Rex Thompson

Cox School of Business, Southern Methodist University

Karin S. Thorburn

Norwegian School of Economics

(C) Sandra Betton, B. Espen Eckbo, Rex Thompson and Karin S. Thorburn 2013. All rights reserved. Short sections of text, not to exceed two paragraphs, may be quoted without explicit permission provided that full credit, including (C) notice, is given to the source.

This paper can be downloaded without charge from: http://ssrn.com/abstract_id= 1835073

www.ecgi.org/wp 


\title{
Merger Negotiations with Stock Market Feedback
}

\author{
Working Paper $N^{\circ} .392 / 2013$ \\ November 2013 \\ Sandra Betton \\ B. Espen Eckbo \\ Rex Thompson \\ Karin S. Thorburn
}

\begin{abstract}
For helpful comments and discussions, we thank the Editor (Cam Harvey), an Associate Editor and two anonymous referees, Laurent Bach, Eric de Bodt, Michael Lemmon, Pablo Moran, and Annette Poulsen. This paper, and an early precursor entitled "Markup pricing revisited", also benetted from comments received in faculty seminars at the following universities and business schools: Aarhus, Adelaide, Arizona, Boston, Calgary, Cambridge, City University of Hong Kong, Colorado, Connecticut, Dartmouth, Georgia, HEC Montreal, Lille, LBS, Lund, Maryland, Melbourne, Navarra, Norwegian School of Economics, BI Norwegian School of Management, Notre Dame, Oregon, Oxford, SMU, Stavanger, Texas A\&M, Texas Tech, Tilburg, Tulane, York, and UBC. The paper was also presented at the association meetings of the AFA, EFA, EFMA, FMA, FMAI, and the NFA, as well as at the Paris Spring Corporate Finance Conference and the UBC Summer Finance Conference. Partial nancial support from Tuck's Lindenauer Center for Corporate Governance is gratefully acknowledged.
\end{abstract}

(C) Sandra Betton, B. Espen Eckbo, Rex Thompson and Karin S. Thorburn 2013. All rights reserved. Short sections of text, not to exceed two paragraphs, may be quoted without explicit permission provided that full credit, including (C) notice, is given to the source. 


\begin{abstract}
Do pre-offer target stock price runups increase bidder takeover costs? We present modelbased tests of this issue assuming runups are caused by signals that inform investors about potential takeover synergies. Rational deal anticipation implies a relation between target runups and markups (offer value less the runup) that is greater than minus one-forone and inherently nonlinear. If merger negotiations force bidders to raise the offer with the runup --- a costly feedback loop where bidders pay twice for anticipated target synergies --- markups become strictly increasing in runups. Large-sample tests support rational deal anticipation in runups while strongly rejecting the costly feedback loop.
\end{abstract}

Keywords: Takeovers, offer premium, runup, markup, feedback loop

JEL Classifications: G34

Sandra Betton

Associate Professor of Finance

Concordia University - Department of Finance

1455 de Maisonneuve Blvd. Wes

Montreal, Canada

phone: +514-848-2783 , fax: +514-848-4500

e-mail: sbett@jmsb.concordia.ca

B. Espen Eckbo*

Tuck Centennial Professor of Finance

Dartmouth College - Tuck School of Business

Hanover, USA

phone: +603-646-3953, fax: +603-646-3805

e-mail: b.espen.eckbo@tuck.dartmouth.edu

Rex Thompson

Ph.D.

Southern Methodist University (SMU) - Edwin L. Cox School of Business

P.O. Box 750333

Dallas, USA

phone: +214-768-3052

e-mail: rex@cox.smu.edu

Karin S. Thorburn

Research Chair Professor of Finance

Norwegian School of Economics

Helleveien 30

Bergen, Norway

phone: +4755959283, fax: +4755959543

e-mail: Karin.Thorburn@nhh.no

${ }^{*}$ Corresponding Author 


\title{
Tuck School of Business at Dartmouth
}

\author{
Tuck School of Business Working Paper No. 2011-94
}

\section{Merger negotiations with stock market feedback}

\author{
Sandra Betton \\ John Molson School of Business, Concordia University \\ B. Espen Eckbo \\ Tuck School of Business at Dartmouth \\ Rex Thompson \\ Cox School of Business, Southern Methodist University \\ Karin S. Thorburn \\ Norwegian School of Economics
}

November 2013

Journal of Finance, forthcoming

This paper can be downloaded from the

Social Science Research Network Electronic Paper Collection:

http://ssrn.com/abstract=1835073 


\title{
Merger Negotiations with Stock Market Feedback
}

\author{
Sandra Betton, B. Espen Eckbo, Rex Thompson, and Karin S. Thorburn*
}

\begin{abstract}
Do pre-offer target stock-price runups increase bidder takeover costs? We present modelbased tests of this issue assuming runups are caused by signals that inform investors about potential takeover synergies. Rational deal anticipation implies a relation between target runups and markups (offer value minus runup) that is greater than minus one-for-one and inherently nonlinear. If merger negotiations force bidders to raise the offer with the runupa costly feedback loop where bidders pay twice for anticipated target synergies - markups become strictly increasing in runups. Large-sample tests support rational deal anticipation in runups while rejecting the costly feedback loop.
\end{abstract}

JEL classification: G34

Keywords: Takeovers, offer premium, runup, markup, feedback loop

${ }^{*}$ Betton is at the John Molson School of Business, Concordia University, Eckbo is at the Tuck School of Business at Dartmouth College, Thompson is at the Cox School of Business, Southern Methodist University, and Thorburn is at the Norwegian School of Economics. For helpful comments and discussions, we thank the Editor (Cam Harvey), an Associate Editor and two anonymous referees, Laurent Bach, Eric de Bodt, Michael Lemmon, Pablo Moran, and Annette Poulsen. This paper, and an early precursor entitled "Markup pricing revisited," also benefitted from comments received in faculty seminars at the following universities and business schools: Aarhus, Adelaide, Arizona, Boston, Calgary, Cambridge, City University of Hong Kong, Colorado, Connecticut, Dartmouth, Georgia, HEC Montreal, Lille, LBS, Lund, Maryland, Melbourne, Navarra, Norwegian School of Economics, BI Norwegian School of Management, Notre Dame, Oregon, Oxford, SMU, Stavanger, Texas A\&M, Texas Tech, Tilburg, Tulane, York, and UBC. The paper was also presented at the association meetings of the AFA, EFA, EFMA, FMA, FMAI, and the NFA, as well as at the Paris Spring Corporate Finance Conference and the UBC Summer Finance Conference. Partial financial support from Tuck's Lindenauer Center for Corporate Governance is gratefully acknowledged. 
Takeover bids are typically preceded by substantial target stock price runups. The literature typically characterizes such runups as the discounted value of target deal synergies triggered by takeover rumors. As such, the runups are exogenous to the deal and should not affect deal terms. Yet, Schwert (1996) reports that in a sample of takeovers, the market's valuation of the offer itself is increasing in the runup, almost dollar for dollar. It is as if bidders increase the offer price by the runup, which would amount to paying twice for the target's portion of deal-specific synergies embedded in the runup. In this paper, we develop and empirically test a simple takeover model with rational agents that permits this type of costly feedback loop from target runups to deal terms. Empirical evidence on whether there exists a costly feedback loop is important for parties to takeover negotiations in particular, and for the debate on the efficiency of the takeover mechanism in general.

Our takeover model allows us to characterize the fundamental relation between two observable variables: the runup and the subsequent offer "markup" (the offer value less the runup). Runups are triggered by takeover signals that, importantly, inform investors about both the deal probability and the deal-specific takeover synergies conditional on a bid. Before introducing a costly feedback loop, we show that the basic runup-markup relation implied by rational deal anticipation is much more complex than previously thought: while the conventional intuition is that a dollar increase in the runup will be offset by a dollar decrease in the markup (Schwert (1996) labels this the "substitution hypothesis"), in our model the runup-markup relation is always greater than minus one-for-one, is inherently nonlinear, and may even be positive. Interestingly, we show that this surprising complexity relative to the conventional prediction is driven primarily by the informativeness of our takeover signal, which causes investors to update not only the takeover probability but also the conditional deal value.

To illustrate some of this complexity, suppose that the offer premium does not respond to the runup (no feedback loop) and consider a takeover signal that is low. If the signal informs investors about the takeover probability only (holding the conditional deal value constant), the low signal implies a low runup (low deal probability) followed by a high markup (high deal surprise, driving the low deal probability to one). Now let the takeover signal inform investors 
about conditional deal values as well, so that both the deal value and the deal probability are increasing in the signal. A low signal now results in an even lower runup (low probability times a low deal value). However, this low runup is followed by a low markup as the takeover bid, while producing a high deal surprise, confirms the low anticipated deal value. So, the runup and the markup are now both low relative to the conventional prediction. Conversely, a high signal results in a high runup and also a higher markup than conventionally predicted since deal synergies tend to be high.

Our assumption that the takeover signal informs investors about the level of deal synergies also produces interesting and important implications for the runup-markup relation in the presence of our costly feedback loop: markups are now strictly increasing in the runup. Intuitively, whatever the size of the runup caused by rational deal anticipation, the markup has to be at least as large as the runup or the bidder has not actually paid twice for the synergies embedded in the runup. ${ }^{1}$ Bidders are rational - agreeing to the runup transfer may reflect, for example, time pressure to close a valuable deal. More importantly, the model takes into account the fact that the runup transfer must be financed by the bidder's share of total synergies, and hence the feedback loop deters otherwise marginally profitable bidders. Since the costly runup transfer produces a runup-markup relation that is strictly positive, the costly feedback loop hypothesis is rejected if linear cross-sectional regression of markups on runups produce a negative slope coefficient on the runup.

We offer large-sample tests of these and other nested model predictions, using more than 6,000 initial takeover bids for U.S. public targets in 1980 to 2008. The tests strongly reject the existence of a costly feedback loop as defined in this paper. Importantly, the empirical tests explicitly recognize that the sample target runups may be driven by any combination of deal anticipation (takeover probability times conditional deal synergies) and changes in the target's stand-alone value. We develop an unbiased estimator for the stand-alone value change that implements the intuition that runups of targets with higher stock price volatility should be more likely to be driven by stand-alone value changes. Tests based on runups adjusted for the estimated stand-alone value changes only strengthen our rejection of the costly feedback loop 
hypothesis.

Furthermore, our takeover model delivers testable implications for the correlation between bidder and target takeover-induced stock returns. Since the takeover signal is informative about deal synergies, and since the bidder and target firms in our model share those synergies, it follows that bidder and target takeover-induced abnormal stock returns are positively correlated. Specifically, greater target deal values reflected in higher measured target gains and runups should be associated with greater bidder deal values and announcement returns, which our empirical evidence strongly supports. Interestingly, the finding of a positive correlation between bidder total gains and the target runup constitutes evidence that the takeover signal does indeed inform investors about potential takeover synergies, as absent this information structure, the predicted correlation between bidder gains and target runups is zero.

Finally, we use our model framework to motivate two additional empirical investigations. First, we show that offer premiums change almost one-for-one with the market return over the runup period. It appears that market-driven changes in target value, which are arguably exogenous to the takeover synergy gains, are passed through to the target. Second, we examine the effects of significant trades in the target shares during the runup period. We find that such block trades tend to increase runups regardless of whether the buyer is the initial bidder or some other investor. However, there is no evidence that the additional runup is associated with higher offer premiums. This evidence therefore fails to support the notion that bidder toehold purchases in the runup period, which as we show fuel target runups, also increase takeover costs.

Our paper adds to the growing empirical literature examining possible feedback loops from market prices to corrective actions taken by bidders in takeovers. For example, Luo (2005) and Kau, Linck, and Rubin (2008) report that negative bidder stock returns following initial bid announcements increase the chance of subsequent bid withdrawal. It is as if bidders learn from the information in the negative market reaction and in some cases decide to abandon further merger plans. We do not pursue this issue here as our empirical tests are not impacted by a decision to abandon after the initial offer has been made. However, our findings suggest that the chance of abandonment will be lower for targets with relatively large pre-bid runups, since 
these targets likely represent deals with greater total synergies to be shared with the bidder.

Also, there is an interesting indirect link between our evidence and the findings of recent studies such as Bradley et al. (2010) and Edmans, Goldstein, and Jiang (2012) that link takeover activity to broad stock market movements. It appears that positive marketwide price shocks (exogenous to takeovers) are associated with a reduction in takeover likelihood at the extensive margin. At first, this may seem to contradict our finding that bidder gains in observed bids are increasing in target runups. However, there is no necessary contradiction as we model synergistic takeovers (independent of target stand-alone value changes). That is, while target runups may deter bids driven by attempts to acquire undervalued target assets, bids driven by bidder-specific synergy gains as modeled here remain undeterred - and possibly end up in our sample.

Furthermore, our evidence of deal anticipation in the runup is consistent with extant evidence that target runups in observed bids tend to revert back to zero following bid rejection (Bradley, Desai, and Kim (1983) and Betton, Eckbo, and Thorburn (2009)). This characterizes the unsuccessful bids in our sample as well. The logic here is that runups that discount expected synergy gains from a control change revert back towards zero whenever it becomes clear to the market that the offer will fail. In contrast, if bids are primarily motivated by targets being undervalued by the stock market, and if runups tend to correct the undervaluation, then there is little reason for the runup to revert (perhaps other than a negative signal implied by successful target-management resistance to the takeover attempt). The fitted forms of the markup projection shown in this paper are generally consistent with the former but not with the latter source of takeover gains.

The rest of the paper is organized as follows. Section I develops the takeover model and its testable implications. Section II presents the results of our main empirical tests on the correlation between target runups and markups. Empirical results for bidder stock returns and their correlation with target runups and markups are in Section III, while Section IV examines effects of exogenous shocks to the target value in the runup period. Section V concludes the paper. 


\section{A Takeover Model with Rational Deal Anticipation}

As empirical motivation, Figure 1 illustrates the information arrival process assumed in our analysis, and shows the economic significance of the average target price revision for our sample of 6,150 takeover bids (sample description follows in Section II below). The market receives a rumor (takeover signal) causing investors to anticipate that a synergistic takeover bid will occur with probability $0<\pi \leq 1$, resulting in a target stock price runup of $V_{R}$. In Figure 1 , $V_{R}$ averages a significant $7 \%$ when measured as the abnormal target stock return over the two months prior to the first public offer announcement. Unadjusted for market movements, $V_{R}$ averages $10 \%$.

The subsequent (surprise) offer announcement leads to a second target price revision or "markup" of $V_{P}-V_{R}$, where $V_{P}$ is the market's valuation of the target's deal value conditional on the offer announcement. In the following, we refer to $V_{P}$ as "the conditional target deal value" or just the "target deal value." In Figure 1, the markup averages $22 \%$ when estimated as the target abnormal stock return over the three-day offer announcement period (from day -1 through day +1$)$.

Below, we model the relation between the runup $V_{R}$ and the markup $V_{P}-V_{R}$. We begin in Section I.A with a baseline model that abstracts from the possibility of a costly feedback loop from runups to deal terms. Such a feedback loop is subsequently introduced in Section I.B. In Section I.C, we derive testable implications of our information structure and rational deal anticipation for the relation between bidder and target takeover gains. The central empirical predictions, which are nested within the same theoretical framework, are summarized in Table I at the beginning of Section II.

\section{A. The Baseline Takeover Model}

We normalize to zero both the prior takeover probability and the target stock price before the market receives a takeover signal (so $V_{R}$ and $V_{P}$ are in dollar terms). Let $S$ denote the dollar value of total synergies created by the takeover; $S$ is known to the bidder and target negotiators 
but not to outside investors, who only receive a signal $s$ about $S$. Based on this takeover signal, investors update their prior information to form the posterior probability distribution $G(S \mid s)$ with density $g(S \mid s)$. Moreover, we assume that higher signals $s$ shift $G(S \mid s)$ to the right so that $d E(S \mid s, b i d) / d s>0 .^{2}$

The takeover negotiations split the synergies between bidder and target firms using a known sharing rule $\theta \in(0,1)$, where the bidder receives $\theta S$. The bidder bears a known bidding cost $C$ and will bid only if $S>K$, where $K \equiv C / \theta$ is the bid threshold (minimum synergy level to rationally make a bid). Bidding costs may include things like advisory fees and litigation risk, as well as any opportunity cost of expected synergy gains from a better business combination than the target under consideration. The target receives $B(S) \equiv(1-\theta) S$ from a takeover, with $B(S)=0$ if there is no takeover (and so $S=0$ ). The assumption that $S>0$ only if there is a target control change (a takeover) is supported by evidence on unsuccessful targets both in our sample and in the extant literature (Betton, Eckbo, and Thorburn (2008)).

Let $\bar{B} \equiv E(B(S) \mid s, b i d)$ denote the expected target synergy gains conditional on the signal and the bid. Since the target stand-alone value does not change during the runup period, the target deal value is $V_{P}=\bar{B}$. This market value accounts for any remaining uncertainty, at the time of the initial bid, about the synergy realization from eventual merger consummation. As the market receives the takeover signal, it capitalizes $V_{P}$, yielding the runup

$$
V_{R}=\int_{K}^{\infty} B(S) g(S \mid s) d S=\pi V_{P}
$$

where the takeover probability is given by

$$
\pi=\operatorname{Prob}(S>K)=\int_{K}^{\infty} g(S \mid s) d S
$$

This shows clearly that the takeover signal $s$ impacts the runup positively through the implied probability $\pi$ and through the deal value $V_{P}$, sice $d V_{P} / d s$ has the same sign as $d E(S \mid s, b i d) / d s$. 
Likewise, the signal jointly impacts the markup,

$$
V_{P}-V_{R}=(1-\pi) V_{P}
$$

but the markup is impacted positively through $V_{P}$ and negatively through $(1-\pi)$.

Figure 2 illustrates these valuation functions under uniform uncertainty, $S \mid s \sim U(s-\Delta, s+$ $\Delta)$, with density $g(S \mid s)=1 /(2 \Delta)$ and parameter values $\theta=0.5, C=0.5$, and $\Delta=4$. The closed forms of the nonlinear functions in the figure, including proof that it reaches a maximum, are shown in the Appendix. Rational bidding requires $s>K-\Delta$ for a bid to occur with positive probability, which is the starting value for $s$ along the horizontal axis in Figure 2, Panel A.

Beginning with the target deal value $V_{P}$, it increases linearly with $s$ after a minimum value of $(1-\theta) K$ when $s$ just exceeds $K-\Delta$. Note that this minimum value is increasing in $C$ because, with rational bidders, feasible bids must produce sufficient synergies to cover bidding costs. Given a low signal $s$, if $C=0$, the minimum value of $V_{P}$ is small as $S$ tends to be close to zero in observed bids. Conversely, a high $C$ cuts off low-value bidders, which increases the conditional expected value of $S \mid s$ and therefore the minimum value of $V_{P}$.

Next, the runup $V_{R}=\pi V_{P}$ starts at zero and increases in a convex fashion with the signal. At low signals, $V_{R}$ is close to zero because bidders are near indifferent to making offers (both $\pi$ and $V_{P}$ are low), while higher signals mean both higher deal probabilities and greater conditional deal values. The markup function $V_{P}-V_{R}$ is highly nonlinear and concave for $K-\Delta<s \leq K+\Delta$, where $0<\pi \leq 1$. Because $K<\Delta$ in the figure, the markup reaches a maximum at $s=0$, and with the uniform distribution declines to zero when $s>K+\Delta .^{3}$

Intuitively, for low signal values, the markup is low because the deal announcement tends to confirm the low target deal value $V_{P}$ anticipated by the market. As the signal increases, the positive effect on the deal value $V_{P}$ initially dominates the negative effect of the signal on the deal surprise $1-\pi$, causing the markup to increase with the signal strength. Following the inflexion point (for $s=0$ ), the reverse happens: the decline in deal surprise from greater signal values dominates the increase in deal value, and the markup decreases in the signal. ${ }^{4}$ 
To make this theory testable, we transform the unobservable signal $s$ to the observable runup $V_{R}$. This transformation is possible because both $V_{P}$ and $V_{R}$ are monotonic in $s$ and have inverses. Combining equations (1) and (3) yields what we refer to as the "markup projection":

$$
V_{P}-V_{R}=\frac{1-\pi}{\pi} V_{R}
$$

This pricing relation is a direct implication of rational deal anticipation (market efficiency): it adjusts for the takeover probability $\pi$ so as to hold for observed bids. Also, the form of equation (4) is general in that it does not depend on the form of the target benefit function $B(S)$, the size of the threshold value $K$, or the distributional properties of $S \mid s$.

Moreover, the form of equation (4) is also preserved if we add a known target stand-alone value change of $T$ dollars over the runup period that is exogenous to the takeover process. In that case, the bidder raises the offer by $T$ (so the target receives $T$ regardless of whether a bid occurs) without reducing bidder synergy gains. Equation (4) remains unchanged except that $T$ must now be subtracted from the observed runup on the right-hand side in order to isolate $V_{R}$ (the portion of the observed runup related to takeover synergies only). ${ }^{5}$

The markup projection in (4) clarifies an important assumption implicit in traditional linear regression tests for deal anticipation in runups (as in Schwert (1996)). Write the markup projection using the linear form

$$
V_{P}-V_{R}=a+b V_{R}
$$

where $a$ and $b$ are regression constants. The traditional prediction is $b=-1$ : a dollar increase in runup is offset by a dollar decrease in markup. Equating (5) and (4), and replacing $V_{R}$ with $\pi V_{P}$, yields

$$
\frac{1}{\pi}-1=\frac{a}{\pi V_{P}}+b
$$

Equation 6 says that for the markup projection to be linear with $b=-1$, it must also be the case that $V_{P}=a$. In other words, the traditional test requires that the target deal value is crosssectionally constant. In terms of the information environment, this is equivalent to assuming 
that the takeover signal received by the market in the runup period is uninformative about the takeover synergies created by the deal (and so $d V_{P} / d s=0$ ).

Proposition 1 identifies an important, empirically testable restriction on the linear slope coefficient $b$ when $V_{P}$ is not constant and the general markup projection holds:

PROPOSITION 1: Suppose the markup projection (4) holds. When the takeover signal causes the market to infer different takeover probabilities and conditional deal values across a sample of takeovers $\left(d \pi / d s>0\right.$ and $\left.d V_{P} / d s>0\right)$, then the linear regression (5) produces a slope coefficient $b$ that is strictly greater than -1 .

Proof: The derivative of the markup projection (4) w.r.t the signal $s$ is ${ }^{6}$

$$
\frac{\frac{d}{d s}(1-\pi) V_{P}}{\frac{d}{d s} \pi V_{P}}=\frac{-V_{P} \frac{d \pi}{d s}+(1-\pi) \frac{d V_{P}}{d s}}{V_{P} \frac{d \pi}{d s}+\pi \frac{d V_{P}}{d s}}=\frac{-\left(A_{1}+A_{2}\right)+\frac{d V_{P}}{d s}}{A_{1}+A_{2}}>-1
$$

where $A_{1} \equiv V_{P} \frac{d \pi}{d s}$ and $A_{2} \equiv \pi \frac{d V_{P}}{d s}$. Since $d V_{P} / d s>0$ and $d \pi / d s>0$ over the range where $V_{P}>0$ and $0<\pi<1$, both $A_{1}$ and $A_{2}$ are positive.

Figure 2, Panel B illustrates how the markup varies with the runup when the distribution of $S \mid s$ is uniform (the solid curve) as well as normal (broken curve, scaled to have the same mean deviation). The slope of the markup projection is clearly nonconstant when $0<\pi<1$. The intuition for this nonlinearity is analogous to that presented for Figure 2, Panel A above. The slope at the left-hand tail again depends on the bidding costs C. Because $K<\Delta$ in the figure (bid costs are low relative to the synergy uncertainty), the slope starts positive for low $V_{R}$ and reaches a maximum before trending negative. The slope at the right-hand tail drops towards zero because the deal probability approaches one (and becomes zero with the uniform distribution but not with the normal uncertainty as the probability never reaches one). ${ }^{7}$ 


\section{B. The Markup Projection with Costly Feedback Loop}

In this section we introduce a costly feedback loop from target runups to deal terms. The feedback loop means that the bidder transfers the runup to the target through a higher offer price. The target valuation conditional on the offer is now

$$
V_{P}^{*}=\bar{B}^{*}+V_{R}^{*}
$$

where $\bar{B}^{*} \equiv E^{*}(B(S) \mid s$, bid $)$ and the superscript * indicates values computed using the new bid threshold $K^{*} \equiv\left(C+V_{R}^{*}\right) / \theta>K$. The runup transfer (the second term in equation (8)) must be financed from the bidder's net takeover gains. As illustrated below, relative to the case without a costly feedback loop, the higher bid threshold $K^{*}$ lowers the takeover probability and increases the target deal value conditional on a bid.

Using (8), the feedback loop implies a runup of

$$
V_{R}^{*}=\pi^{*} V_{P}^{*}=\frac{\pi^{*}}{1-\pi^{*}} \bar{B}^{*}
$$

and a markup of

$$
V_{P}^{*}-V_{R}^{*}=\bar{B}^{*}
$$

That is, the markup equals the conditional target deal value itself. The intuition is simple: the markup now consists of the surprise target deal value (as before) plus the surprise runup transfer, which sum to the total deal value. ${ }^{8}$

Figure 3, Panel A illustrates the runup and markup with costly feedback loop as functions of the signal $s$, again assuming a uniform distribution for $S \mid s$ and with parameter values as in Figure 2. As before, the runup is increasing over the range of the takeover signal $s$. More importantly, now the markup is also increasing over the entire signal range. As the runup increases with $s$, offers where bidder net synergy gains become too small to finance the runup transfer are eliminated or withdrawn, causing the conditional target deal value $V_{P}^{*}$ to increase.

Figure 3, Panel A also plots the probability $\pi^{*}$ (right vertical axis). Since $K^{*}>K$, it follows 
that $\pi^{*}<\pi$ for all values of $s$. This lowering of the deal probability is quite dramatic: when $s=K+\Delta$, which is a signal value that in Figure 2, Panel A produces a certain bid, $\pi^{*}=0.37$ in Figure 3, Panel A.

Also, since the runup transfer must be financed from the bidder's portion of the takeover gains, $\pi^{*}$ must be less than $\theta$. To see why, note that the bidder gains with a runup transfer is $\theta S-C-V_{R}^{*}$. Let $\bar{S}^{*} \equiv E^{*}(S \mid s, b i d)$. The condition for positive expected bidder net gains is

$$
\theta \bar{S}^{*}-C-\frac{\pi^{*}}{1-\pi^{*}}(1-\theta) \bar{S}^{*}>0
$$

which reduces to

$$
\pi^{*}<\frac{\theta \bar{S}^{*}-C}{\bar{S}^{*}-C}
$$

As $s \rightarrow \infty$, the right-hand side of equation (12) converges towards $\theta$ (which has a value of 0.5 in Figure 3, Panel A).

PROPOSITION 2: Suppose the markup projection (4) holds. When merger negotiations force rational bidders to raise the offer price with the runup (costly feedback loop), the markup becomes a positive and monotonic function of the runup, and the linear markup regression (5) yields a positive slope coefficient $(b>0)$.

Proof: Since the markup projection (4) also holds for the case with a costly feedback loop, we can write

$$
V_{P}^{*}-V_{R}^{*}=\frac{1-\pi^{*}}{\pi^{*}} V_{R}^{*}
$$

For the slope to be positive, $d\left(V_{P}^{*}-V_{R}^{*}\right) / d s$ and $d V_{R}^{*} / d s$ must have the same sign. Since $B$ is increasing in $S$ and $E^{*}(S)$ increases in $s$, it is straightforward that $d\left(V_{P}^{*}-V_{R}^{*}\right) / d s=d \bar{B}^{*} / d s>0$. Moreover, using (9) we have that

$$
\frac{d V_{R}^{*}}{d s}=\frac{\bar{B}^{*}}{\left(1-\pi^{*}\right)^{2}} \frac{d \pi^{*}}{d s}+\frac{\pi^{*}}{1-\pi^{*}} \frac{d \bar{B}^{*}}{d s}
$$


Using Leibnitz rule and noting that $d K^{*} / d s=(1 / \theta)\left(d V_{R}^{*} / d s\right)$,

$$
\frac{d \pi^{*}}{d s}=\int_{K^{*}}^{\infty} g^{\prime}(S \mid s) d S-\frac{g\left(K^{*}\right)}{\theta} \frac{d V_{R}^{*}}{d s}
$$

where $g^{\prime}(S \mid s)$ is the first derivative of $g(S \mid s)$. Substituting (14) into (13) and rearranging yields

$$
\frac{d V_{R}^{*}}{d s}=\left[\frac{\bar{B}^{*}}{\left(1-\pi^{*}\right)^{2}} \int_{K^{*}}^{\infty} g^{\prime}(S \mid s) d s+\frac{\pi^{*}}{1-\pi^{*}} \frac{d \bar{B}^{*}}{d s}\right] /\left[1+\frac{\bar{B}^{*} g\left(K^{*}\right)}{\left(1-\pi^{*}\right)^{2} \theta}\right]>0
$$

Figure 3, Panel B plots the markup projection with a costly runup transfer, again for the uniform case (the shape is similar if we instead assume normal uncertainty). In contrast to Figure 2, Panel B, where the markup falls after reaching a maximum value, the markup in Figure 3, Panel B is monotonically increasing in the runup, approaching a near-linear form for low values of $V_{R}$. It is therefore straightforward that the costly feedback loop hypothesis is rejected if a linear markup regression produces a statistically significant negative slope in a sample of takeovers.

\section{Deal Anticipation and Bidder Returns}

Finally, we turn to the relation between bidder and target valuations in our model. As for targets, the bidder stock price is normalized to zero prior to the runup period. Given the sharing rule $0<\theta<1$, and abstracting from a costly feedback loop, greater total synergies $S$ result in greater bidder gains $A=\theta S-C$. The takeover signal results in a runup in the bidder's market value, and a subsequent bid further raises this market value as bid uncertainty is resolved. Let $\nu_{P}$ denote the market's valuation of the bidder conditional on the bid: $\nu_{P} \equiv E(A(S) \mid s$, bid $)$. With no change in the bidder stand-alone values during the runup period, we have that

$$
\nu_{P}=\frac{1}{\pi} \int_{K}^{\infty} A(S) g(S \mid s) d S
$$

PROPOSITION 3: (i) Suppose the takeover signal causes the market to infer different takeover 
probabilities and conditional deal values across a sample of takeovers $\left(d \pi / d s>0\right.$ and $d V_{P} / d s>$ 0). Absent a costly feedback loop, rational market deal anticipation implies $\operatorname{Cov}(A, B)>0$ and $\operatorname{Cov}\left(A, V_{R}\right)>0$. (ii) If the takeover signal is uninformative about deal values (d $/ d s>0$ and $\left.d V_{P} / d s=0\right)$, then $\operatorname{Cov}\left(A, V_{R}\right)=0$ absent a costly feedback loop, and $\operatorname{Cov}\left(A, V_{R}\right)<0$ in the presence of a costly feedback loop.

Proof: In part (i) of the proposition: $\operatorname{Cov}(A, B)=\operatorname{Cov}(\theta S-C,(1-\theta) S)=\theta(1-\theta) \operatorname{Var}(S)>$ 0. For the sign of $\operatorname{Cov}\left(E<V_{R}\right)$, note that the observed $S$ equals its conditional expectation $\bar{S} \equiv E(S \mid s, b i d)$ plus noise. Thus, $\operatorname{Cov}\left(A, V_{R}\right)=\operatorname{Cov}(\theta S-C,(1-\theta) \pi \bar{S})=\theta(1-\theta) \operatorname{Cov}(\bar{S}, \pi \bar{S})$.

Since both $\bar{S}$ and $\pi$ are increasing in $s$, this covariance is positive. In part (ii) of the proposition, consider first the case without a costly feedback loop. Since both firms share $S$ (which is ran$\operatorname{dom}), \operatorname{Cov}(A, B)>0$. However, $\operatorname{Cov}(S, s)=0$ since $s$ is uninformative about deal value and so $\bar{S}$ does not vary with $s$. Thus, $\operatorname{Cov}\left(A, V_{R}\right)=0$. Adding a costly feedback loop, bidders transfer more of the synergy gains to the target as anticipation increases while, by assumption, the total expected synergy gains remain constant. Thus, gains to the bidder decrease on average with increasing target runups: $\operatorname{Cov}\left(A, V_{R}\right)<0 .^{9}$

We now turn to a large-scale empirical analysis of the above propositions and related hypotheses.

\section{Testing for Deal Anticipation and Costly Feedback Loop}

\section{A. Empirical Test Strategy}

Table I summarizes the central empirical hypotheses nested within the rational deal anticipation framework developed above. The first column repeats the theoretical form of the economic model, while the second and third columns describe the associated econometric model and (a total of 11) empirical tests. We begin with the baseline deal anticipation hypothesis (Proposition 1), which states that, under deal anticipation, the predicted value of the linear slope coefficient is $b>-1$. Moreover, the general markup function (4) is inherently nonlinear, as illustrated in 
Figure 2, Panel B. We explore the presence of nonlinearities using a flexible functional form (the beta function), and perform several goodness-of-fit tests for nonlinearity against the hypothesis that the markup projection is linear.

The estimates of the linear slope coefficient $b$ provide a direct test of the costly feedback loop hypothesis, which predicts that the markup should be increasing everywhere in the runup (Proposition 2). A statistically significant negative slope coefficient in the linear markup regression would therefore constitute a powerful rejection of the existence of our costly feedback loop hypothesis. Combining Propositions 1 and 2, finding $-1<b \leq 0$ simultaneously would reject the existence of a costly feedback loop while supporting rational deal anticipation in runups.

While not modeled explicitly in Section I, the empirical analysis also addresses the possibility of a change of $T$ dollars (positive or negative) in the target's stand-alone value during the runup period. The presence of a known $T$ does not affect the above theory. However, it attenuates the slope coefficient and reduces power to detect nonlinearities in the runup-markup relation implied by the synergy component itself. More specifically, while $T$ does not affect the markup (as the difference between the premium and the runup automatically nets out $T$ ), it introduces an errors-in-variables problem in the runup. We therefore develop an estimator for $T$ that allows us to subtract the estimated value of $T$ from the observed total runup, and repeat the key empirical tests with the adjusted runup (the estimated synergy component) as the independent variable.

Rational deal anticipation and rational bidding further imply that bidder takeover gains are related in specific ways to the target gains and runup (Proposition 3). The predictions in Proposition 3 are tested using linear regressions of $\nu_{P}$ on $V_{P}$ and $V_{R}$. Under alternative (i) in the proposition, the linear slope of both these target valuations is predicted to be positive. In part (ii), however, which assumes that the takeover signal is uninformative about deal synergies (the information structure implicit in the extant literature, as discussed in equation (6) above), the predicted linear slope coefficient on $V_{R}$ is zero absent a costly feedback loop and negative in the presence of a costly feedback loop.

The empirical analysis also examines (in Section IV) two additional linear regression spec- 
ifications that address potential offer price effects of known shocks to the target runup. The first is the (exogenous) market return over the runup period, and the second is a major block trade in the target shares such as a bidder toehold purchase. We test whether either of these two factors fuel target runups and, if so, if they result in increased offer prices.

\section{B. Characteristics of the Takeover Sample}

As summarized in Table II, we sample control bids from SDC using transaction form "merger" or "acquisition of majority interest," requiring the target to be publicly traded and U.S. domiciled. The sample period is January 1980 to December 2008. In a control bid, the buyer owns less than $50 \%$ of the target shares prior to the bid and seeks to own at least $50 \%$ of the target equity.

We group bids into takeover contests. A takeover contest may have multiple bidders, several bid revisions by a single bidder, or a single control bid. The initial control bid is the first control bid for the target in six months. All control bids announced within six months of an earlier control bid belong to the same contest. The contest ends when there are no new control bids for the target over a six-month period or the target is delisted. This definition results in 13,893 takeover contests. We then require that targets (i) are listed on NYSE, Amex, or NASDAQ, (ii) have at least 100 days of common stock return data in CRSP over the estimation period (day -297 through day -43), (iii) have total market equity capitalization exceeding $\$ 10$ million on day -42 , (iv) have a stock price exceeding $\$ 1$ on day -42 , (v) have an offer price in SDC, (vi) have a stock price in CRSP on day -2 , (vii) have an announcement return for the window $[-1,+1]$, (viii) have information on the outcome and ending date of the contest, and (ix) have a contest length of 252 trading days (one year) or less. The final sample has 6,150 control contests.

Approximately three-quarters of the control bids are merger offers and $10 \%$ are followed by a bid revision or competing offer from a rival bidder. The frequency of tender offers and multiplebid contests is higher in the first half of the sample period. The initial bidder wins control of the target in two-thirds of the contests, with a higher success probability towards the end of the sample period. One-fifth of the control bids are horizontal. A bid is horizontal if the target and 
acquirer have the same four-digit SIC code in CRSP or, when the acquirer is private, the same four-digit SIC code in SDC. Based on the major four-digit SIC code of the target, approximately one-third of the sample targets are in manufacturing industries, one-quarter are in the financial industry, and one-quarter are service companies. The remaining targets are spread over natural resources, trade, and other industries.

Table III shows average premiums, markups, and runups, both annually and for the total sample. The initial offer premium is $\frac{O P}{P_{-42}}-1$, where $O P$ is the initial offer price and $P_{-42}$ is the target stock closing price or, if missing, the bid-ask average on trading day -42 , adjusted

Table III here for splits and dividends. The bid is announced on day 0. Offer prices are from SDC. The offer premium averages $45 \%$ for the total sample, with a median of $38 \%$. Offer premiums were highest in the 1980s when the frequency of tender offers and hostile bids was also greater, and lowest after 2003.

The next two columns show the total markup, $\frac{O P}{P_{-2}}-1$, which is the ratio of the offer price to the target stock price on day -2 . The total markup is $33 \%$ for the average control bid (median $27 \%$ ). The target total runup, defined as $\frac{P_{-2}}{P_{-42}}-1$, averages $10 \%$ for the full sample (median $7 \%$ ), which is roughly one-quarter of the offer premium. The last two columns of Table III show the net runup, defined as the runup net of the average market runup $\left(\frac{M_{-2}}{M_{-42}}-1\right.$, where $\mathrm{M}$ is the value of the equal-weighted market portfolio). The net runup is $8 \%$ on average, with a median of $5 \%$.

\section{Estimating the Markup Projections using Offer Prices}

Table IV shows the results of estimating the markup projection for our sample of 6,150 initial takeover bids. For each model, the table shows the constant term and slope from estimating the baseline linear markup projection, along with three test statistics for nonlinearity. All estimates are produced using the beta distribution, denoted $\Lambda(v, w)$, where $v$ and $w$ are shape parameters determined by the data:

$$
V_{P j}-V_{R j}=a+b \frac{\left(V_{R j}-\min \right)^{(v-1)}\left(\max -V_{R j}\right)^{w-1}}{\Lambda(v, w)(\max -\min )^{v+w-1}}+\epsilon_{j}, \quad j=1, \ldots, N
$$


Here, $\max$ and $\min$ are, respectively, the maximum and minimum $V_{R}$ in the data, $a$ is an overall intercept, $b$ is a scale parameter, and $\epsilon_{j}$ is a residual error term. The estimated shape parameters $v$ and $w$ determine whether the beta density suggests the projection is concave, convex, peaked at the left, right, or both tails, unimodal with the hump toward the right or left, or linear. A least squares fit over all four parameters allows the data to find a best nonlinear shape using the beta density. If the parameters are constrained to $v=1$ and $w=2$ or vice versa, a least squares fit (allowing $a$ and $b$ to vary) produces an $a$ and $b$ that replicate the intercept and slope coefficient in a linear (OLS) regression (reported in Table IV).

Beginning with the first hypothesis in Table I (linear slope $b>-1$ and nonlinearity), recall Table IV here that Figure 2, Panel B suggests a unimodal fit with the hump to the left and the right tail declining towards zero as the takeover signal increases and deals become increasingly certain. Figure 4, Panel A plots our sample total runups and total markups as defined in model (1) of Table IV using three alternative estimated functions: (i) the best linear fit (constrained to have $v=1$ and $w=2$ or vice versa), (ii) the best nonlinear monotone fit (constrained to have $v \leq 1$ ), and (iii) the best nonlinear fit (unconstrained) of the markup on the runup.

The unconstrained empirical fit in Figure 4, Panel A is quite similar to the theoretical shapes Figure 4 here in Figure 2, Panel B. The hump to the left in Figure 4, Panel A is driven by a subset of takeovers with low runups. Takeovers of poorly performing targets are not uncommon - about one-third of the sample runups are negative - reflecting negative changes in the target's stand-alone value during the runup period. We return to an adjustment for negative runups in Section II.D below.

The last three columns in Table IV show three goodness-of-fit likelihood ratio $(L R)$ test statistics applied to the data in Figure 4, Panel A. The likelihood ratio is calculated as $L R=\left(\frac{S S E \text { (constrained model })}{S S E(\text { unconstrained model })}\right)^{\frac{N}{2}}$, where $S S E$ is the sum of squared errors for the constrained and the unconstrained model specifications, and $N$ is the sample size. For large samples, $-2 \ln (L R) \sim \chi^{2}(d)$, where $d$ is the number of model restrictions (Theil (1971), p. 396). We have verified that this likelihood ratio test statistic shows close correspondence to a $\chi^{2}$ distribution near the $1 \%$ significance level when using simulated linear markups with normal errors.

Of the three $L R$ statistics in Table IV, the first, $L R 1$, tests for nonlinearity against the 
alternative of a linear form $(d=2)$. The second, $L R 2$, tests nonlinearity against monotonicity $(d=1)$. The third, $L R 3 \equiv L R 1-L R 2$, tests monotonicity against linearity $(d=1)$. The $1 \%$ critical value for $L R 1$ is 9.2 , while for $L R 2$ and $L R 3$ it is 6.6 . With the exception of $L R 3$ for models (3) and (4) in Table IV, where runups and markups are measured using cumulative abnormal returns (CARs) rather than offer prices, all the reported $L R$ values substantially exceed their respective $1 \%$ cutoff points. All the $L R 1$ values across all the models strongly reject linearity in favor of the unrestricted nonlinear form. Moreover, all the $L R 2$ values reject monotonicity in favor of nonmonotonicity. Finally, with the exception of models (3) and (4), the $L R 3$ values also reject linearity against monotonicity.

The results of the linear regressions in Table IV are important. Recall from Proposition 1 that the baseline deal anticipation hypothesis predicts a linear slope coefficient of $b>-1$. The estimated slope coefficients reported in Table IV have values that are significantly greater than -1 , with the exception of model (2) where $b=-1.01$ (discussed further below). For example, the estimated slope coefficient for model (1) is -0.24 , which has a $t$-statistic of -11.9 against zero and (not reported) a $t$-statistic of 37.7 against -1 . Moreover, the slope coefficient estimates across all seven models are negative and significantly different from zero. This evidence simultaneously rejects our costly feedback loop hypothesis, where the bidder pays twice for the portion of target runup caused by anticipation of takeover synergies (i.e., $b>0$ ), and supports the hypothesis that runups reflect rational deal anticipation.

\section{Adjusting Runups for Target Stand-Alone Value Changes}

In this section, we consider the effect of adding a stand-alone value change of $T_{j}$ dollars (positive or negative) to the value of target $j$ in the runup period. The stand-alone value change $T_{j}$ represents an exogenous change in the value of the target resources in their second-best use. While unobservable to the econometrician, we assume that $T_{j}$ is known to the negotiators, perhaps inferred from secondary market trading in the target shares during the runup period. Since $T_{j}$ does not impact the synergy $S_{j}$ or the takeover probability $\pi_{j}, T_{j}$ is neither a source of takeover gains in our model nor a takeover cost if transferred to the target. Thus, the incentive 
to bid continues to be driven by bidder net synergies only.

Let $V_{R j}$ denote a runup that includes $T_{j} \neq 0$. Assuming the runup flows through to the target (at zero cost to the bidder), we have that

$$
V_{R j}=\pi \bar{B}_{j}+T_{j}
$$

where $\pi \bar{B}_{j} \equiv \pi_{j} E\left(B_{j}(S) \mid s, b i d\right)$. Our empirical results above (model (1) in Table IV and Figure 4, Panel A) show that the nonlinearity predicted by the deal anticipation component $\pi \bar{B}_{j}$ appears in the data even without adjusting for sample variation in $T_{j}$. Nevertheless, we are interested in whether isolating $\pi \bar{B}_{j}$ in the data improves the nonlinear empirical fit of the markup projection in Figure 4, Panel A. In particular, subtracting an estimate of $T_{j}$ from $V_{R j}$ should increase test power when $V_{R j}$ is negative since, in our model, $V_{R j}<0$ means that $T_{j}<0$ and is greater in magnitude than the positive $\pi \bar{B}_{j}$. In our sample, the total runup is negative in $31 \%$ of the sample bids (in 37\% when we estimate the runup using CARs), perhaps driven by relatively poor target operating performance and/or financial distress.

Assume that $E\left(T_{j}\right)$ is cross-sectionally constant and equal to zero. (A nonzero value of $E\left(T_{j}\right.$ ) would shift the best linear unbiased estimator (BLUE) estimates below by a constant and thus preserve their cross-sectional properties. Moreover, when measuring runups using CARs, that is when netting out price movements due to systematic risk, market efficiency implies $E\left(T_{j}\right)=0$ unconditionally). Given observations on the total runup $V_{R j}$, the following constitutes a BLUE for $T_{j}$ :

$$
E\left(T_{j} \mid V_{R j}\right)=\alpha_{j}+\beta_{j} V_{R j}
$$

Since $T_{j}$ is uncorrelated with the synergy gains, the slope coefficient is

$$
\beta_{j}=\frac{\operatorname{Cov}\left(T_{j}, V_{R j}\right)}{\operatorname{Var}\left(V_{R j}\right)}=\frac{\operatorname{Var}\left(T_{j}\right)}{\operatorname{Var}\left(T_{j}\right)+\operatorname{Var}\left(\pi \bar{B}_{j}\right)},
$$

and the intercept term is $\alpha_{j}=-\beta_{j} E\left(V_{R j}\right)$. 
The BLUE estimate of the partial anticipation component $\pi \bar{B}_{j}$ becomes

$$
\widehat{\bar{B}}_{j}=V_{R j}-E\left(T_{j} \mid V_{R j}\right)=\left(1-\beta_{j}\right) V_{R j}+\beta_{j} E\left(V_{R j}\right) .
$$

This estimator - also referred to below as Adjusted runup — nets out an unbiased estimate of $T_{j}$ from the observed $V_{R j}$. The adjustment implements the idea that a higher observed runup likely has a higher $T_{j}$, but not on a one-for-one basis as $\operatorname{Var}\left(\pi \bar{B}_{j}\right)>0$ implies $\beta_{j}<1$ in equation (20). Moreover, $\beta_{j}$ is smaller the smaller is $\operatorname{Var}\left(T_{j}\right)$ relative to $\operatorname{Var}\left(\pi \bar{B}_{j}\right)$. Thus, when computing the adjusted runup in equation (21), the smaller is $\operatorname{Var}\left(T_{j}\right)$ relative to $\operatorname{Var}\left(\pi \bar{B}_{j}\right)$, the more (less) weight is placed on the observed runup $V_{R j}\left(E\left(V_{R j}\right)\right)$.

The BLUE estimator requires estimation of the parameters $E\left(V_{R j}\right), \operatorname{Var}\left(T_{j}\right)$, and $\operatorname{Var}\left(\pi \bar{B}_{j}\right)$. Since $E\left(T_{j}\right)=0$, equation (18) implies that $E\left(V_{R j}\right)=E\left(\pi \bar{B}_{j}\right)$, which we estimate as the crosssectional average observed runup $\bar{V}_{R}$. We estimate the runup two ways: as the total runup $\left[\left(p_{-2} / p_{-42}\right)-1\right]$ and as the target's $\operatorname{CAR}(-41,-2)$ (the CAR estimation uses the market model; see details in Section II.E below). In our sample, $\bar{V}_{R}=9.8 \%$ when based on the total runup, and $7.3 \%$ when based on the CAR runup.

Second, $\operatorname{Var}\left(T_{j}\right)$ is estimated as $\operatorname{Var}\left[C A R_{j}(-81,-42)\right]$, defined as the time-series variance of the target's CAR over the 40-day pre-runup period from day -81 through day -42 ; $\operatorname{Var}\left[C A R_{j}(-81,-42)\right]$ reflects the time-series variability of $T_{j}$ without being contaminated by $\operatorname{Var}\left(\bar{B}_{j}\right)$. Assuming time-series independence in the daily abnormal stock returns, $\operatorname{Var}\left[C A R_{j}(-81,-42)\right]$ is estimated as the variance of the daily abnormal stock return times 40 .

Finally, we estimate $\operatorname{Var}(\pi \bar{B})$ as $\operatorname{Var}[C A R(-41,-2)]-\operatorname{Var}[C A R(-81,-42)]$, the difference in the cross-sectional CAR variances over the runup period and the pre-runup period. This difference in variances captures the notion that signals of synergy gains add variability to the cross-section of total runups relative to an equivalent period that is not influenced by realizations of $s$. In our sample, when estimated this way, $\operatorname{Var}(\pi \bar{B})$ is $24 \%$ of the average estimate of $\operatorname{Var}\left(T_{j}\right)$ described above.

Combining these estimates produces an average estimated $\beta$ in equation (20) of 0.77 , with 
a minimum of 0.74 and a maximum of 0.99 . Using the $\beta$ estimates to adjust the runups in equation (21) successfully pulls in the tails of the runup data: when we use the total runup, the minimum runup increases from $-83 \%$ to $-12 \%$ and the maximum drops from $244 \%$ to $67 \%$. The percentage of negative runups falls from a third of the sample to less than $3 \%$ of the sample (146 cases). Within our model, these observations contain negative estimation error despite the adjustment.

The results of the linear and nonlinear fits using the adjusted total runups are shown as model (2) in Table IV and plotted in Figure 4, Panel B. Because we are reducing the spread in runups, the linear slope is accentuated, at -1.01 , strongly negative and insignificantly different from -1. This estimate is sensitive to our estimate of $\beta$ in the adjustment model, and the other two model estimates with adjustments (models (4) and (7)) produce linear slopes that are significantly greater than -1 as predicted. It is also interesting that the adjustment in model (2) improves the nonlinear fit over model (1): Figure 4, Panel B shows a definite hump in the left portion of the runups, and the $L R 1$ and $L R 2$ test statistics are considerably higher at 125.6 and 64.5 , respectively.

Our BLUE estimator provides an interesting interpretation of how the components $T_{j}$ and $\bar{B}_{j}$ may be varying in the cross-section of observed runups. First, the amount of $T$ in the average deal, which has a total runup of about $10 \%$, is zero (the entire $10 \%$ reflects average anticipation of deal synergies). Second, deals with greater than average runups experience a positive standalone value change in the runup period, where $T_{j}$ is estimated using $\beta_{j}\left(V_{R j}-E\left(V_{R j}\right)\right)$ in equation (21). Conversely, deals with runups of less than $10 \%$ experience $T_{j}<0$ in the runup period.

\section{E. The Markup Projection Estimated using CARs}

While our main empirical analysis uses offer premiums to measure markups, in this section we instead define markups using CARs in response to the takeover bid announcement. This provides a link back to the work of Schwert (1996), who also uses CARs to estimate markups. In models (3) and (4) in Table IV, CAR is estimated using the market model, where the runup is $\operatorname{CAR}(-41,-2)$ and the markup is $\operatorname{CAR}(-1,1)$. While Schwert (1996) employs a long event 
window to measure markups, from day 0 through day 126 relative to the offer announcement, we prefer the shorter window $(-1,1)$ to minimize the effect on the markup estimate of subsequent takeover-related events, including bid revisions and withdrawal information. The parameters of the market model are estimated on stock returns from day -297 through day -42 , and the CAR uses the model prediction errors over the event period.

Like Schwert (1996), model (3) makes no adjustment in the CAR for target stand-alone value changes $(T)$ in the runup period beyond that achieved by subtracting the influence of market movements on target stock returns. In model (4), however, as in model (2), we subtract an estimate of $T$ using our BLUE estimator in equation (19). The fitted form of model (4) is shown in Figure 5.

Although the measurement error in CAR lowers test power, the likelihood ratio test statistics $L R 1$ and $L R 2$ again strongly reject linearity, in both models (3) and (4). According to LR3, the best monotone fit is now indistinguishable from the linear fit (that is, if we do not allow the fit to permit a hump, the model is almost linear), a result not critical for our deal anticipation theory. Interestingly, the nonlinear fit is significantly enhanced by the adjustment for the target standalone value change in model (4). This is also reflected in the linear slope coefficient going from -0.09 in model (3) to -0.39 in model (4), suggesting a substantially greater degree of substitution on average between runups and markups when we isolate the deal synergy component in the runup, as our theory predicts.

In sum, empirical models (1) to (4) in Table IV support the presence of deal anticipation in target runups, while at the same time rejecting the hypothesis that merger negotiations force bidders to systematically raise offer prices with the runup. This conclusion fails to support the view that target runups increase bidder takeover costs in observed takeover bids.

\section{F. Robustness}

In this section, we report the results of two robustness checks on model (1) in Table IV. The first check, implemented in models (5) and (6), adjusts the offer price markup for an estimate of the bid success probability given the bid announcement. The second robustness check, in model 
(7), adds information available to the market prior to the runup period, which may help predict takeovers.

\section{F.1. The Probability of Bid Success}

When estimating the deal value $V_{P}$ using offer premiums, the estimate does not account for the probability that the offer will ultimately be accepted by target shareholders. Some bids fail, in which case the target receives zero premium. Presumably, the market reaction to the bid adjusts for an estimate of the probability of an ultimate control change. This is apparent from Figure 1 where the target stock price on average runs up to just below $30 \%(\mathrm{CAR}(-41,1)=29 \%)$, while the average offer premium in Table III is $37 \%$ adjusted for the market runup. To account for this effect, in this section we multiply the initial offer price by an estimate of the target success probability (where target failure means that no bidder wins the contest).

The success probability is estimated using logit, where the dependent variable takes a value of one if the target (according to the SDC) is ultimately acquired either by the initial bidder or a rival bidder, and zero otherwise. The explanatory variables are as defined in Table $\mathrm{V}$ and the results of the logit estimation are reported in the first two columns of Table VI.

The logit regressions for contest success are significant with a pseudo- $R^{2}$ of $21 \%$ to $22 \%$. The difference between the first and second columns is that the latter includes two dummy variables for the 1990s and the 2000s. The probability that the takeover is successful increases significantly with the size of the target, and is higher for public acquirers and in horizontal transactions. Bids for targets traded on NYSE or Amex, targets with relatively high stock turnover (average daily trading volume, defined as the ratio of the number of shares traded and the number of shares outstanding, over days -252 to -43 ), and targets with a poison pill have a lower likelihood of succeeding.

A high offer premium also tends to increase the probability of takeover success, as does a relatively small run-down from the 52-week high target stock price. Moreover, the coefficients on dummy variables indicating a positive bidder toehold in the target (Toehold), stock consideration exceeding $20 \%$ of the bidder's shares outstanding and hence requiring acquirer shareholder 
approval (>20\% new equity), and a hostile (as opposed to friendly or neutral) target reaction (Hostile) are all negative and significant. Finally, contests starting with a tender offer are more likely to succeed, as are contests announced in the 1990s and the 2000s. The dummy variable indicating an all-cash bid generates a significantly negative coefficient only when controlling for the time period (column (2)).

Table VI, columns (3) to (6), also shows the coefficients from logit estimations of the probability that the initial control bidder wins the takeover contest. The pseudo- $R^{2}$ is somewhat higher for this success probability, ranging from $22 \%$ to $28 \%$. Columns (3) and (4) use the same models as the earlier estimations of contest success, while columns (5) and (6) add a variable capturing the percent of target shares owned by the initial control bidder at the time of the bid (Toehold size). Almost all explanatory variables generate coefficients that are similar in size, direction, and significance level to those in the logit regressions of contest success. The reason is that in the vast majority of successful contests, it is the initial bidder who wins control of the target. The only difference between the probability estimations is that the existence of a target poison pill does not substantially affect the likelihood that the initial bidder wins. The larger the initial bidder toehold, however, the greater is the probability that the initial bidder wins.

There are a total of 6,103 targets with available data on the characteristics used in the logit estimation. For each of these targets, we multiply the total markup by the estimated success probability computed using the second model in Table VI (which includes the two decade dummies). This expected markup is then used in models (5) and (6) reported in Table IV. Model (5) uses the total runup, while model (6) uses the total runup adjusted using the BLUE estimator for the target stand-alone value change.

Consistent with our baseline deal anticipation hypothesis, the linear slope coefficient estimates are negative and greater than -1 for both models. Moreover, the likelihood ratio tests $L R 1$ and $L R 2$ for both models strongly reject linearity and monotonicity against nonlinearity, while $L R 3$ also rejects linearity against monotonicity. ${ }^{10}$ 


\section{F.2. Information Prior to the Runup Period}

Up to this point, we have assumed that the market imparts a negligible likelihood of a takeover onto the target price before the beginning of the runup period (day -41 in Figure 1). To start the runup period around two calender months prior to the first bid is common in the empirical takeover literature, beginning with Bradley (1980). Moreover, the large markups in our data (on average $33 \%$, Table III) indicate that the offer announcement is a significant news (surprise) event. Nevertheless, in this section we check whether including information prior to day -41 in the computation of the runup changes our empirical results.

Suppose the market has already received a signal $z$ on event day -42 . Moreover, the market receives a second signal $s$ during the runup period. Now, a bid is made if $s+z$ exceeds a threshold level of synergy gains. Working through the valuations, there is one important change. Define $V_{0}=\pi(z) E(B(S) \mid z)$ as the expected value of takeover prospects at the end of event day -42 given $z$ and a diffuse prior on $s$. The runup and the bid premium are now measured relative to $V_{0}$ instead of zero,

$$
V_{R}-V_{0}=\pi(s+z) E(B(S) \mid s+z, b i d)-\pi(z) E(B(S) \mid z),
$$

and the premium is

$$
V_{P}-V_{0}=E(B(S) \mid s+z, b i d)-\pi(z) E(B(S) \mid z)=\frac{1}{\pi(s+z)}\left(V_{R}-V_{0}\right)
$$

In other words, to investigate the nonlinear influence of market anticipation prior to the runup period, one must add back $V_{0}$ to both the runup and the bid premium. Since the influence of $V_{0}$ is a negative one-for-one on both quantities, markups are not affected.

To unwind the influence of a possibly known takeover signal $z$ prior to the runup period, we use the following three deal characteristics defined earlier in Table V: Toehold, Toehold size, and the negative value of 52-week high. A toehold means that at some point in the past the bidder acquired a toehold in the target, which may have caused some market anticipation of a 
future takeover. Moreover, it is reasonable to assume that the signal is increasing in the size of the toehold. Also, we know from Baker, Pan, and Wurgler (2012) and Table IX below that the target's 52-week high return impacts the takeover premium.

Using these variables, model (7) in Table IV implements two multivariate adjustments to the model baseline in row (1). The first adjustment, as dictated by equation (22), augments the runup by adding $R_{0}$, where $R_{0}$ is the projection of the total runup $\left(\frac{P_{-2}}{P_{-42}}-1\right)$ on Toehold, Toehold size, and the negative value of 52-week high. The second adjustment is to use as the dependent variable the "residual markup" $U_{P}$, which is the residual from the projection of the total markup, $\frac{O P}{P_{-2}}-1$, on the deal characteristics used to estimate the success probability $\pi$ in Table VI while excluding Toehold, Toehold size, and 52-week high, which are used to construct the augmented runup.

Model (7) in Table IV shows the linear and nonlinear projections of the residual markup on the augmented runup. The linear slope remains negative and highly significant (slope of -0.26 , $t$-statistics of -12.1). Thus, the costly feedback hypothesis continues to be rejected with the augmented runups. Moreover, the three $L R$ test statistics confirm that the goodness-of-fit of the nonlinear form of the markup projection is significantly better than those of the linear and the monotonic forms, and that monotonicity fits better than linearity. Overall, this evidence further supports the presence of a deal anticipation effect in the runup measured over the runup period.

\section{Do Bidders Share in Total Synergy Gains?}

Proposition 3, as summarized in Table I above, states that when the takeover signal informs investors about deal synergies $\left(d V_{P} / d s>0\right)$, and the bidder and target share in the takeover gains, total bidder gains are positively correlated with both target total gains $(\operatorname{Cov}(A, B)>0)$ and the target runup $\left(\operatorname{Cov}\left(A, V_{R}\right)>0\right)$. Intuitively, rational market anticipation of shared takeover gains increases the stock prices of both bidders and targets. Alternatively, if we restrict the takeover signal to be uninformative about deal synergies $\left(d V_{P} / d s=0\right)$, rational deal 
anticipation implies $\operatorname{Cov}\left(A, V_{R}\right)=0$. Moreover, if we maintain $d V_{P} / d s=0$ and also add a costly feedback loop, rational deal anticipation implies $\operatorname{Cov}\left(A, V_{R}\right)<0$.

We test these predictions using the 3,691 publicly traded bidders in our sample. Our estimate of total bidder gains, $\nu_{P}$, is the cumulative abnormal bidder stock return (BCAR) from event day -41 through the day following the first public bid announcement, $\operatorname{BCAR}(-41,1)$. As for the target CAR analysis in Section II.E above, the estimation of BCAR uses a market model regression estimated over the period from day -297 through day -42 relative to the initial offer announcement date.

We examine the relation between $\operatorname{BCAR}(-41,1)$ and target total gains and runups in two ways. First, Figure 6 shows the functional form when $\operatorname{BCAR}(-41,1)$ is projected on the target runup using the nonlinear form (equation (17)). Here, the target runup is CAR(-41,-2) in Figure 6, Panel A, and is Adjusted CAR(-41,-2) in Figure 6, Panel B, where the target runup adjustment uses the BLUE estimator from Section II.D for target stand-alone value changes. Second, we estimate the slope coefficients in multivariate linear regressions of BCAR on target gains and alternative definitions of the target runup, reported in Table VII.

As is well known, bidder announcement returns are noisy (Betton, Eckbo, and Thorburn (2008)). In our sample, BCAR(-41,1) averages a statistically insignificant -1.5\%. From Moeller, Schlingemann, and Stulz (2005) we also know that bidder announcement returns are unusually negative in the two-year period 1999 to 2000. In our sample, BCAR(-41,1) averages a significant $-4.7 \%$ across our 529 observations from these two years. Thus, we add an intercept dummy for 1999 to 2000 to our set of control variables in the cross-sectional regressions with $\operatorname{BCAR}(-41,1)$ as the dependent variable.

The empirical projections in Figure 6 are increasing and concave over the entire range of target runups for both runup measures. The likelihood ratio tests we used for targets in Table IV above reject linearity of the shapes in Figure 6 in favor of a nonlinear, monotonically increasing shape. In separate analysis, we also show that the nonlinear shapes are almost identical when $\operatorname{BCAR}(-41,1)$ is projected on the augmented target runup (defined earlier in Table IV) and on target total gains CAR(-41,1). 
Turning to the linear regressions in Table VII, the key independent variables are the target total gains and the target runup. To save space, the table suppresses the individual slope coefficients for most of the remaining regressors referred to collectively as "control variables" as explained in the table caption. Total target gains are estimated as the market model target CAR $(-41,1)$. The target runup variable is estimated in three ways: the market model CAR($41,-2)$, the market model adjusted $\operatorname{CAR}(-41,-2)$ and the net runup, defined as the target total runup net of the market runup $\left(P_{-2} / P_{-42}-M_{-2} / M_{-42}\right)$.

Notice that the six intercept terms in Table VII range from $-1.0 \%$ to $-5.2 \%$, while the 1999 to 2000 period indicator ranges from $-3.2 \%$ to $-4.1 \%$. Inclusion of the control variables raises the regression $R^{2}$ to a high of $6 \%$. Of the control variables, Relative size and All cash receive significantly positive coefficients, while target share turnover (Turnover) receives a significantly negative coefficient.

As predicted (Proposition 3), bidder gains are increasing in both total target gains and target runups. The coefficient on Target $C A R(-41,1)$ is 0.101 (model $(1)$ ) and, with control variables, 0.099 (model (2)), both highly significant. Consistent with the impression given by the nonlinear shapes in Figure 6, the target runup receives a positive and significant coefficient in all six models in Table VII. In model (3), which uses the market model CAR(-41,-2) as the target runup, the coefficient on the runup is 0.149 ( $p$-value $<0.001)$. With the control variables (model (4)), the slope coefficient is a virtually unchanged 0.147. In model (5), where the target CAR runup is adjusted for the BLUE estimator of the target stand-alone value change, the slope coefficient is 0.649 ( $p$-value $<0.001)$ with control variables. In model $(6)$, where the target runup is simply the net runup, the slope coefficient is 0.079 , again highly significant. ${ }^{11}$

Overall, the significantly positive correlations between bidder and target gains in Figure 6 and Table VII strongly support the joint hypothesis that takeover signals inform rational investors about potential deal synergies and that bidders and targets share in the takeover gains. Conversely, the same evidence rejects the alternative hypothesis that the takeover signal is uninformative about potential deal values (which, as discussed above, predicts a zero correlation between bidder and target gains). The same evidence also rejects a second alternative hypothesis: 
that bidders systematically accept value-decreasing deals.

\section{Premium Effects of Shocks to Target Runups}

In this section we examine the effect on the runup and the offer premium of target stock price shocks during the runup period using two instruments. The first is given by significant block trades in the target shares. The second is the market return over the runup period, which affects the target stand-alone value. The empirical effects of these instruments complement the analyses in Sections II and III above, examining the hypothesis that target runups reflect deal anticipation, and whether runups are costly for bidders.

\section{A. Target Share Block Trades (Toehold Purchases)}

We identify toehold purchases using the "acquisitions of partial interest" data item in SDC, where the buyer seeks to own less than $50 \%$ of the target shares. As shown in Table VIII, over the six months preceding bid announcement [-126,0], the initial control bidders in our sample acquire a total of 136 toeholds in 122 unique target firms. Of these stakes, 104 toeholds in 94 different targets are purchased over the 42 trading days leading up to and including the day of the announcement of the initial control bid. Thus, less than $2 \%$ of our initial control bidders acquire a toehold in the runup period. The typical toehold acquired by the initial bidder in the runup period is relatively large, with a mean of $12 \%$ (median $9 \%$ ). Note that this evidence on toehold acquisitions in the runup period is new to the literature as existing papers do not distinguish toeholds held long term from those purchased shortly before the takeover bid (e.g., Betton and Eckbo (2000) and Betton, Eckbo, and Thorburn (2009)).

Also, the timing of the toehold purchase during the runup period is important for its ability to generate takeover rumors. In our sample, two-thirds of the initial control bidders' toehold acquisitions in the runup period are announced on the day of or the day before the initial control bid $[-1,0]$. Since the SEC allows investors 10 days to file a $13(\mathrm{~d})$, these toeholds have most likely been purchased sometime within the 10-day period preceding and including the offer 
announcement day. For these cases, the target stock price runup does not contain information from a public Schedule 13(d) disclosure (but will of course still reflect any market microstructure impact of the trades). The remaining short-term toeholds are all disclosed in the runup period.

We also collect toehold purchases by rival control bidders (appearing later in the contest) and other investors. As it turns out, rival bidders acquire a toehold in the runup period for only three target firms. The average size of these rival short-term toeholds is $7 \%$. Other investors, not bidding for control in the contest, acquire toeholds in 73 target firms (1\% of target firms) during the 42 days preceding the control bid. The announcement of $21 \%$ (18 of 85 ) of these toeholds coincides with the announcement of the initial control bid, suggesting that rumors may trigger toehold purchases by other investors.

Table IX reports results of regressions with the target net runup (columns (1) and (2)) and the offer premium (columns (3) to (6)) as dependent variables. These regressions test for the impact of toehold acquisitions in the runup period, and whether this impact in turn affects offer premiums. The dummy variables Stake bidder and Stake other indicate toehold purchases by the initial control bidder and any other bidder (including rivals), respectively, in the runup window through day 0 . The regressions also control for the bidder's total toehold position at the bid (Toehold size), which includes toeholds that the bidder has held for longer periods. Notice that both Stake bidder and Stake other have a significant and positive impact on the net runup. At the same time, Toehold size enters with a negative and significant sign. Thus, only short-term toehold purchases have a positive impact on target runups.

Several of the other control variables for the target net runup in Table IX receive significant coefficients. The smaller the target firm (Target size) and the greater the relative drop in the target stock price from its 52-week high (52-week high), the higher the runup. Moreover, the runup is higher when the acquirer is publicly traded and for tender offers, and lower for horizontal takeovers. The inclusion of year fixed effects in the second column does not change any of the results. Also, these conclusions remain unchanged if we include a Heckman (1979) correction for endogeneity of the toehold purchase decision (the estimated Mill's ratio) in Table IX. 
In columns (3) to (6) of Table IX, Toehold size receives a statistically significant and negative coefficient in all four offer premium regressions. That is, as reported elsewhere in the literature (Betton and Eckbo (2000), Betton, Eckbo, and Thorburn (2009)), bidders with toeholds pay significantly lower premiums. More important for this paper, the two indicators for shortterm toehold purchases (Stake bidder and Stake other) do not affect offer premiums. An explanation consistent with these results is that, while short-term toehold acquisitions tend to increase runups, the negotiating parties identify this toehold effect as endogenous to the takeover process and thus do not raise the offer in response.

\section{B. Market Movements Over the Runup Period}

In Section II.D above, we adjust the target runup for an estimate of the stand-alone value change $T_{j}$ over the runup period and estimate the markup projection using the adjusted runups. In this section, we instead identify an a priori observable proxy for $T_{j}$ and test whether it affects offer premiums as our theory suggests it should. Continuing the notation from Section II.D, the target bid premium is

$$
V_{P j}=\bar{B}_{j}+T_{j}
$$

while, as in equation (18), the runup is $V_{R j}=\pi \bar{B}_{j}+T_{j}$. Since both $V_{R j}$ and $V_{P j}$ include $T_{j}$, the effect of $T_{j}$ nets out in the markup: $V_{P j}-V_{R j}=(1-\pi) \bar{B}_{j}$. Substituting these expressions into the markup projection (4) and rearranging yields

$$
V_{P j}=\frac{1}{\pi}\left(V_{R j}-T_{j}\right)+T_{j}
$$

Equation (25) is stated in terms of the observable offer premium and the runup. It indicates that the net runup $V_{R j}-T_{j}$ should be unrelated to a proxy for $T_{j}$, so the one-for-one relation between the offer premium and the proxy for $T_{j}$ should hold in a univariate setting. ${ }^{12} \mathrm{We}$ therefore examine equation (25) using the linear regressions reported in Table IX.

Candidate proxies for $T_{j}$ considered in this section include factors that affect the offer premium through the target market value but are uncorrelated with takeover likelihood. Candidates 
are the cumulative market return over the runup period, a CAPM benchmark (beta times the market return), or the target industry return. All of these are subject to their own varying degrees of measurement error. We select perhaps the simplest measure, the market return during the runup period or Market runup. As it turns out, more complex measures such as the market-adjusted industry return over the runup period do not add explanatory power to the regressions reported in Table IX.

Columns (1) and (2) in Table IX show that Net runup is linearly related to Market runup. Since our theory predicts that these two variables should be uncorrelated, we use Whitened net runup in the premium regressions, where Whitened net runup is the unstandardized residuals from a regression of Net runup on Market runup.

As expected from equation (25), columns (3) to (6) show that the coefficient on Market runup is highly significant and close to unity in all four offer premium regressions. This is evidence that merger negotiations allow the market-driven portion of the target return to flow through to the target in the form of a higher offer premium - on virtually a one-to-one basis. Also as expected, the variable Whitened net runup is highly significant when included as an explanatory variable for the offer premium. Inclusion of Whitened net runup substantially increases the regression $R^{2}$ (from approximately $8 \%$ to $34 \%$ ) without significantly altering the size of the coefficient on Market runup.

The offer premium regressions also show that premiums are decreasing in Target size and in 52-week high, both of which are highly significant. The significance of 52-week high for our offer premiums is consistent with the recent findings of Baker, Pan, and Wurgler (2012). Moreover, offer premiums are higher for tender offers and when the acquirer is publicly traded. The greater offer premiums paid by public over private bidders is also reported by Bargeron et al. (2008).

\section{Conclusion}

We investigate whether pre-bid target stock price runups increase bidder takeover costs - an issue of first-order importance for the efficiency of the takeover mechanism. We base our predic- 
tions on a simple model with rational market participants and synergistic takeovers. Takeover signals (rumors) received by the market cause market anticipation of deal synergies that drive stock price runups. The model delivers the equilibrium pricing relation between the runup and the subsequent offer price markup (the surprise effect of the bid announcement) that should exist in a sample of observed bids.

A key model innovation is to allow the takeover signal to inform investors about potential takeover synergies, so that a stronger signal implies higher expected synergies and deal values. While this type of signal seems reasonable, it creates a runup-markup relation that is more complex than previously thought. Specifically, in settings where offer prices do not respond to runups, runups are conventionally though to be offset dollar-for-dollar by a decrease in the markup. We show that this prediction presumes that the takeover signal is uninformative about deal synergies. The runup-markup relation with our more informative takeover signal is always greater than minus one-for-one and is inherently nonlinear, which our large-sample evidence supports.

We next add a costly feedback loop from runups to offer premiums to the model. In this loop, merger negotiations cause the bidder to transfer the runup to the target although the runup is driven by market anticipation of target deal synergies - the bidder effectively pays twice for anticipated target deal synergies embedded in the runup. Importantly, the costly feedback loop implies a strictly positive relation between runups and markups, a prediction that our empirical analysis rejects.

This empirical conclusion is robust to the method used to estimate runups and markups. In particular, adjusting target runups for an unbiased estimate of target stand-alone value changes over the runup period only strengthens the rejection. Our evidence therefore presents a strong rejection of the notion that runups increase bidder takeover costs: specifically, bidders do not pay twice for anticipated deal synergies embedded in runups.

A further perspective on the presence of deal anticipation in runups is provided by studying bidder returns. In our model, bidders act rationally and share in the takeover synergies. This implies that, when the market anticipates a synergistic takeover and target runups do not 
increase the offer premium, bidder gains will be increasing in both the target runup and total target gains. This prediction is a direct implication of our assumption that the takeover signal informs investors about conditional deal values in addition to takeover probabilities. The empirical evidence strongly supports this prediction, which in and of itself contributes to the ongoing debate over the existence of bidder takeover gains but also lends support to the basic information structure underpinning our theoretical analysis.

Finally, we examine direct effects on the offer premium of exogenous shocks to the target stock price during the runup period. We show that block trades in the target, including bidder toehold purchases, tend to fuel target runups without increasing offer premiums (if anything, premiums are lower in bids where those trades occur). Moreover, the market return over the runup period is found to flow through to target shareholders by an almost dollar-for-dollar increase in the offer premium. This type of flow-through is reasonable as it does not increase bidder takeover costs.

What if, contrary to our model, the market were to systematically ignore the information in takeover signals (a type of market inefficiency)? This alternative hypothesis implies that markups will be independent of runups. Since our empirical tests strongly reject a zero linear slope in the projection of markups on runups, and confirm that the projection is nonlinear, this alternative market inefficiency hypothesis is rejected. 


\section{Appendix: Valuation Functions with Uniform Uncertainty}

Figure 2 plots target valuation functions with uniform uncertainty: $G(S \mid s) \sim U(s-\Delta, s+\Delta)$ and $g(S \mid s)=1 /(2 \Delta)$ with $\Delta=4$. Moreover, in the figure, bidding costs are $C=0.5$ and the synergy sharing rule is $\theta=0.5$, so the threshold synergy value for a rational bidder to make an offer is $K=C / \theta=1$. Bids are possible but uncertain $(0<\pi<1)$ for $K-\Delta<s<K+\Delta$. The bid probability $\pi$ and the valuation functions $V_{P}=V_{R} / \pi, V_{R}$, and $V_{P}-V_{R}$ are, respectively,

$$
\begin{gathered}
\pi=\int_{K}^{s+\Delta} g(S \mid s) d S=(s+\Delta-K) /(2 \Delta), \\
V_{P}=\frac{1}{\pi} \int_{K}^{s+\Delta}(1-\theta) S g(S \mid s) d S=\frac{1-\theta}{2}(s+\Delta+K), \\
V_{R}=\pi V_{P}=\frac{1-\theta}{4 \Delta}\left((s+\Delta)^{2}-K^{2}\right), \\
V_{P}-V_{R}=\frac{1-\theta}{4 \Delta}\left((K+\Delta)^{2}-s^{2}\right) .
\end{gathered}
$$

The derivatives with respect to $s$ are

$$
\frac{d V_{P}}{d s}=\frac{1-\theta}{2}, \quad \frac{d V_{R}}{d s}=\frac{(1-\theta)(s+\Delta)}{2 \Delta}, \quad \text { and } \quad \frac{d\left(V_{P}-V_{R}\right)}{d s}=-\frac{(1-\theta) s}{2 \Delta},
$$

and so

$$
\frac{d\left(V_{P}-V_{R}\right) / d s}{d V_{R} / d s}=-\frac{s}{s+\Delta}
$$

which is the change in the slope of the markup projection, equation (4), as $s$ changes. For a given $\Delta>0$, this slope is always greater than -1 . The second derivative of this slope can be written as

$$
\frac{d^{2}\left(V_{P}-V_{R}\right)}{d V_{R}^{2}}=\frac{d s}{d V_{R}} \frac{d}{d s}\left[\frac{d\left(V_{P}-V_{R}\right)}{d V_{R}}\right]
$$

Since, by assumption, $d V_{R} / d s>0$ (and the inverse $d s / d V_{R}>0$ ), it follows that

$$
\operatorname{sign}\left(\frac{d^{2}\left(V_{P}-V_{R}\right)}{d V_{R}^{2}}\right)=\operatorname{sign}\left(\frac{d}{d s}\left[\frac{d\left(V_{P}-V_{R}\right)}{d V_{R}}\right]\right) .
$$


The sign is negative because the derivative of (A6) with respect to $s$ is $-\Delta /(s+\Delta)^{2}<0$. This proves that the markup projection shown in Figure 2, Panel B with uniform uncertainty reaches a maximum (for $s=0$ ). 


\section{Footnotes}

${ }^{1}$ With the costly feedback loop, the markup consists of the surprise target deal value (as before) plus the surprise runup transfer, which sum to the total deal value. Details are in Section I.B below.

${ }^{2}$ Large classes of distributions including the normal, lognormal, and uniform distributions have these implications for an upward shift in mean. See, for example, Shaked and Shanthikumar (1994), chapter 1, for a discussion of univariate stochastic orders.

${ }^{3}$ If we instead assume a normal distribution for $S \mid s$ in Figure 2, Panel A, $\pi$ would never reach one and the markup would remain strictly positive over the range of feasible bids.

${ }^{4}$ With uniform uncertainty, high bid costs can create an environment where observed bids only exist on the downward-sloping relation between markup and runup. For example, this happens in Figure 2, Panel A when $K>\Delta$ as bids are then feasible for positive signal values only. However, this special case appears to be driven by the bounded nature of uniform uncertainty. When $S \mid s$ has a normal distribution, our examples invariably show an upward-sloping relation between markup and runup at low signals, followed by a downward-sloping relation, irrespective of bid costs.

5 To illustrate, the runup is now $V_{R T}=\pi E(B(S)+T \mid s$, bid $)+(1-\pi) T=V_{R}+T$, where the subscript $T$ indicates the case with a stand-alone value change. Likewise, $V_{P T}=V_{P}+T$, and so the markup projection with a target stand-alone value change is

$$
V_{P}-V_{R}=\frac{1-\pi}{\pi}\left(V_{R T}-T\right)
$$

which indicates that while observed markups already net out $T$ in the data, $T$ must be estimated to isolate $V_{R}=V_{R T}-T$ in observed runups. We develop an empirical estimator for $T$ in Section II.D below.

${ }^{6}$ Since $V_{R}$ is monotonic in $s$, it has an inverse and so

$$
\frac{d\left(V_{P}-V_{R}\right)}{d V_{R}}=\left(\frac{d\left(V_{P}-V_{R}\right)}{d s}\right)\left(\frac{d s}{d V_{R}}\right)=\frac{\frac{d}{d s}\left(V_{P}-V_{R}\right)}{\frac{d}{d s} V_{R}}=\frac{\frac{d}{d s}(1-\pi) V_{P}}{\frac{d}{d s} \pi V_{P}} .
$$


${ }^{7}$ Interestingly, the empirical results below suggest that actual bidding costs may be sufficiently low to produce an internal maximum for the markup projection, as Figure 2, Panel B illustrates. ${ }^{8} V_{P}^{*}-V_{R}^{*}=(1-\pi) V_{P}^{*}=\left(1-\pi^{*}\right) \bar{B}^{*}+\left(1-\pi^{*}\right) V_{R}^{*}=\bar{B}^{*}$, where the last equality uses $(9)$.

9 This second alternative hypothesis also implies a negative correlation between $\nu_{P}$ and $V_{P}$ if higher transfers from bidders are what drive target gains and not variation in merger synergy gains.

10 These conclusions are unchanged if we restrict the sample to the 5,035 sample targets that actually succeeded (the unconditional success probability is $5,035 / 6,150=0.82$ ).

11 The statistical inferences are similar when we estimate Table VII using the subsample of all-cash offers only.

${ }^{12}$ In the case in which premiums are not increased with changes in stand-alone value, premiums and proxies for changes in stand-alone value should be uncorrelated while the net markup should be negatively correlated with proxies for changes in stand-alone value. 


\section{REFERENCES}

Baker, Malcolm, Xin Pan, and Jeffrey Wurgler, 2012, The effect of reference point prices on mergers and acquisitions, Journal of Financial Economics 106, 49-71.

Bargeron, Leonce, Frederik P. Schlingemann, René M. Stulz, and Chad Zutter, 2008, Why do private acquirers pay so little compared to public acquirers? Journal of Financial Economics 89, 375-390.

Betton, Sandra, and B. Espen Eckbo, 2000, Toeholds, bid jumps, and expected payoff in takeovers, Review of Financial Studies 13, 841-882.

Betton, Sandra, B. Espen Eckbo, and Karin S. Thorburn, 2008, Corporate takeovers, in B. E. Eckbo, ed.: Handbook of Corporate Finance: Empirical Corporate Finance (Elsevier/NorthHolland, Handbooks in Finance Series).

Betton, Sandra, B. Espen Eckbo, and Karin S. Thorburn, 2009, Merger negotiations and the toehold puzzle, Journal of Financial Economics 91, 158-178.

Bradley, Michael, 1980, Interfirm tender offers and the market for corporate control, Journal of Business 53, 345-376.

Bradley, Michael, Alon Brav, Itay Goldstein, and Wei Jiang, 2010, Activist arbitrage: A study of open-ending attempts of closed-end funds, Journal of Financial Economics 95, 1-10.

Bradley, Michael, Anant Desai, and E. Hahn Kim, 1983, The rationale behind inter-firm tender offers: Information or synergy? Journal of Financial Economics 11, 141-153.

Edmans, Alex, Itay Goldstein, and Wei Jiang, 2012, The real effects of financial markets: The impact of prices on takeovers, Journal of Finance 67, 933-971.

Heckman, James J., 1979, Sample selection bias as a specification error, Econometrica 47, 153161.

Kau, James B., James S. Linck, and Paul H. Rubin, 2008, Do managers listen to the market? Journal of Corporate Finance 14, 347-362.

Luo, Yuanzhi, 2005, Do insiders learn from outsiders? Evidence from mergers and acquisitions, Journal of Finance 60, 1951-1982.

Moeller, Sara B., Frederik P. Schlingemann, and René M. Stulz, 2005, Wealth destruction on a 
massive scale? A study of acquiring firm returns in the recent merger wave, Journal of Finance $60,757-782$.

Schwert, G. William, 1996, Markup pricing in mergers and acquisitions, Journal of Financial Economics 41, 153-192.

Shaked, Moshe, and J. George Shanthikumar, 1994, Stochastic Orders and Their Applications (Academic Press, San Diego, CA).

Theil, Henri, 1971, Principles of Econometrics (Wiley, New York).

White, Halbert, 1980, A heteroskedasticity-consistent covariance matrix estimator and a direct test for heteroskedasticity, Econometrica 48, 817-838. 


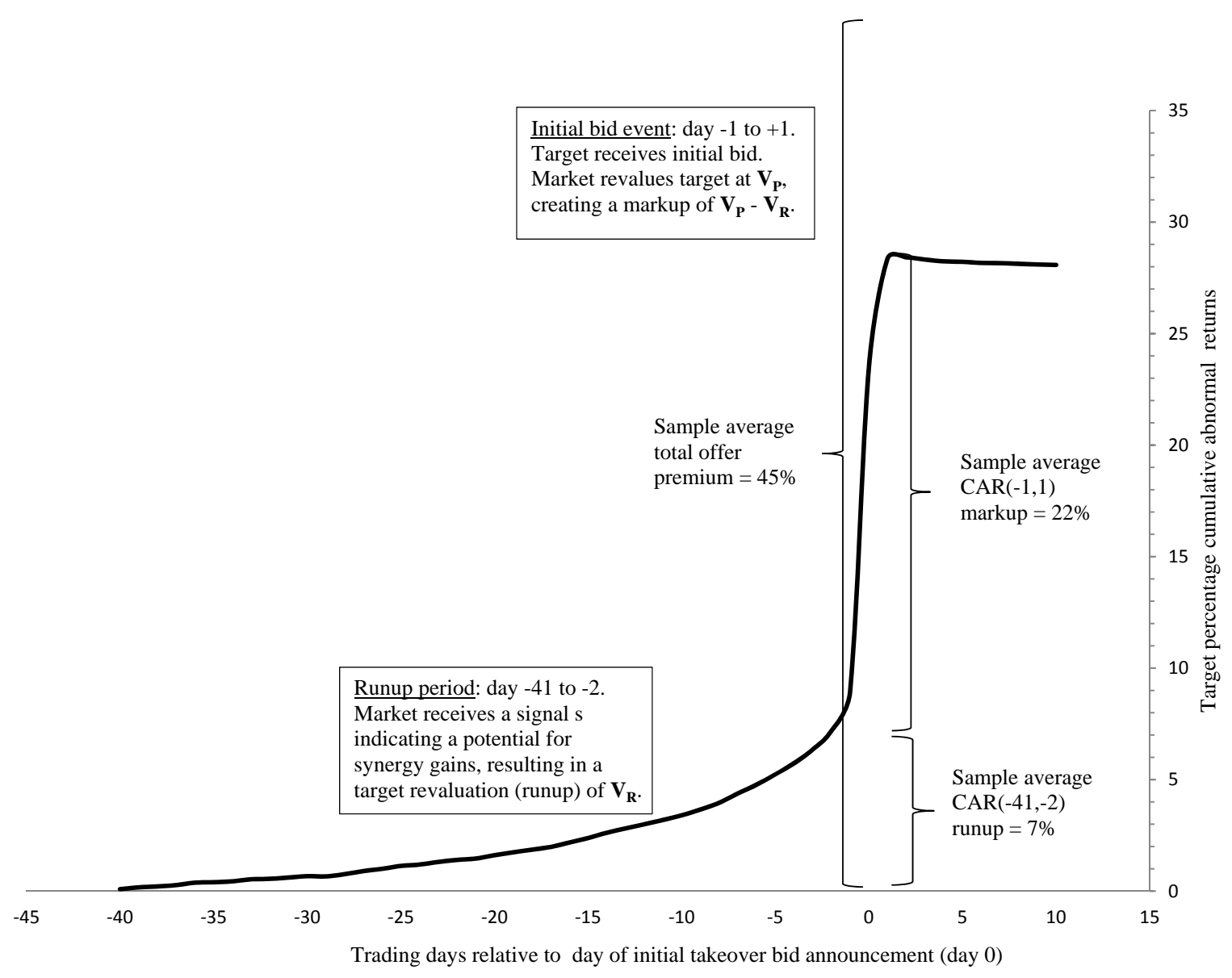

Figure 1. Percent average target runup, markup, and total offer premium in event time. This figure plots the percent average cumulative target abnormal (market risk-adjusted) stock return (CAR) over the runup period (trading day -41 through day -2) and over the announcement period (day -1 through day 1), and the average total initial offer premium $\frac{O P}{p_{-42}}-1$, where $O P$ is the initial offer price and $p_{-42}$ is the target closing price on day -42. The sample comprises 6,150 U.S. public targets over the 1980 to 2008 period. 
Panel A: Target valuation changes with uniform uncertainty

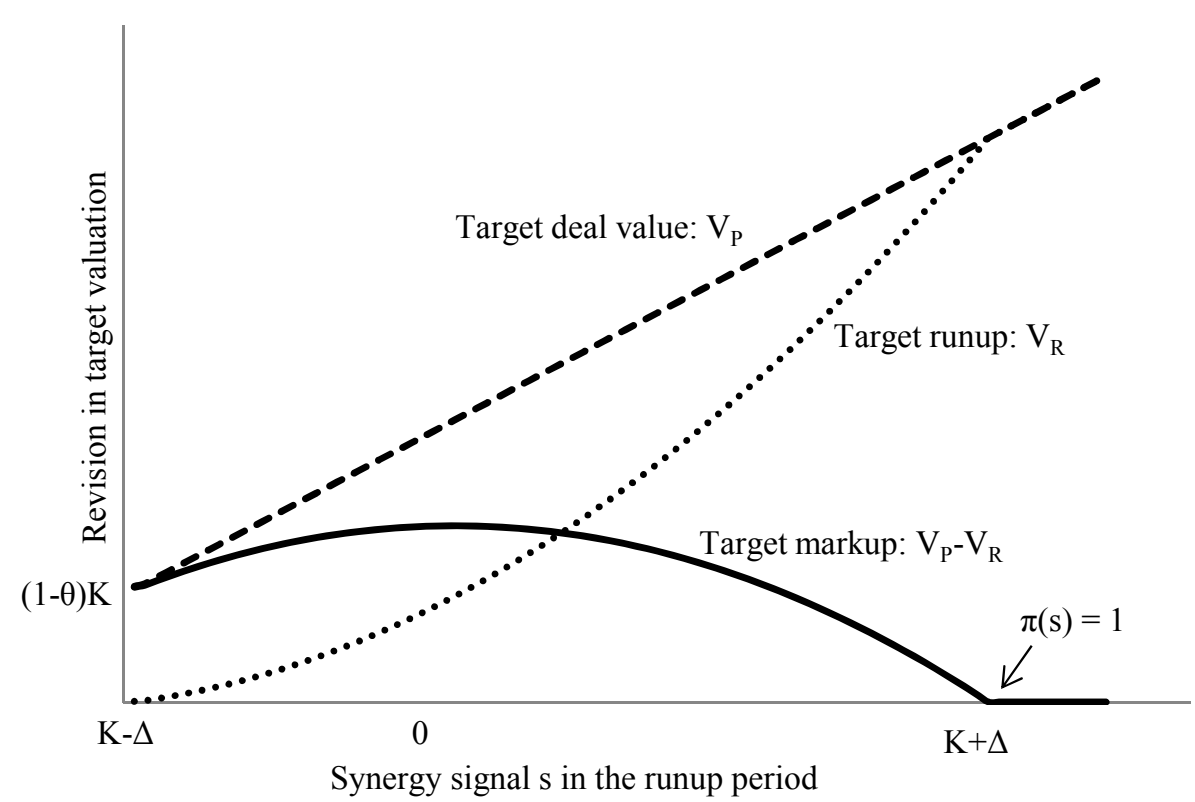

Panel B: Markup projection: $\mathrm{V}_{\mathrm{P}}-\mathrm{V}_{\mathrm{R}}=[(1-\pi) / \pi] \mathrm{V}_{\mathrm{R}}$ with uniform and normal uncertainty

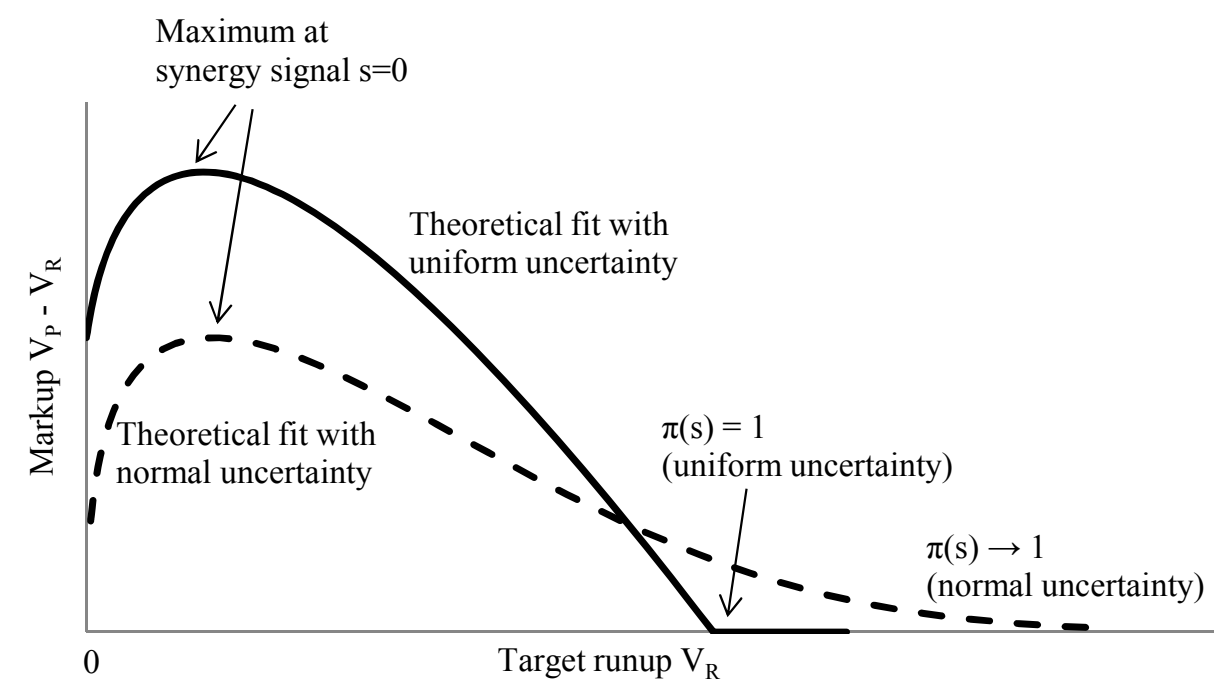

Figure 2. Target valuations and markup projection without costly feedback loop. This figure plots target valuations (Panel A) and markup projection (Panel B) without costly feedback loop. The market receives a signal $s$ (horizontal axis in Panel A) about a potential takeover with synergy $S$, where $S \mid s \sim U(s-\Delta, s+\Delta)$ and $\Delta=4$. The synergy sharing rule is $\theta=0.5$, and bid costs are $C=0.5$ (paid here by the bidder). $V_{R}$ is the target runup, $V_{P}$ is the market's assessment of the target deal value conditional on both $s$ and a bid, $V_{P}-V_{R}$ is the markup, and $\pi=\operatorname{Prob}(S \geq K)$ is the probability of a takeover bid, where $K=C / \theta$ is the bid threshold for bidder gains to be positive and $\pi=1$ for $s \geq K+\Delta$. The solid curve in Panel B is the corresponding markup projection (see the Appendix for the functional forms), while the broken curve in Panel B is the markup projection with a normal distribution for $S \mid s$. 
Panel A: Target valuation changes with transfer of runup to target

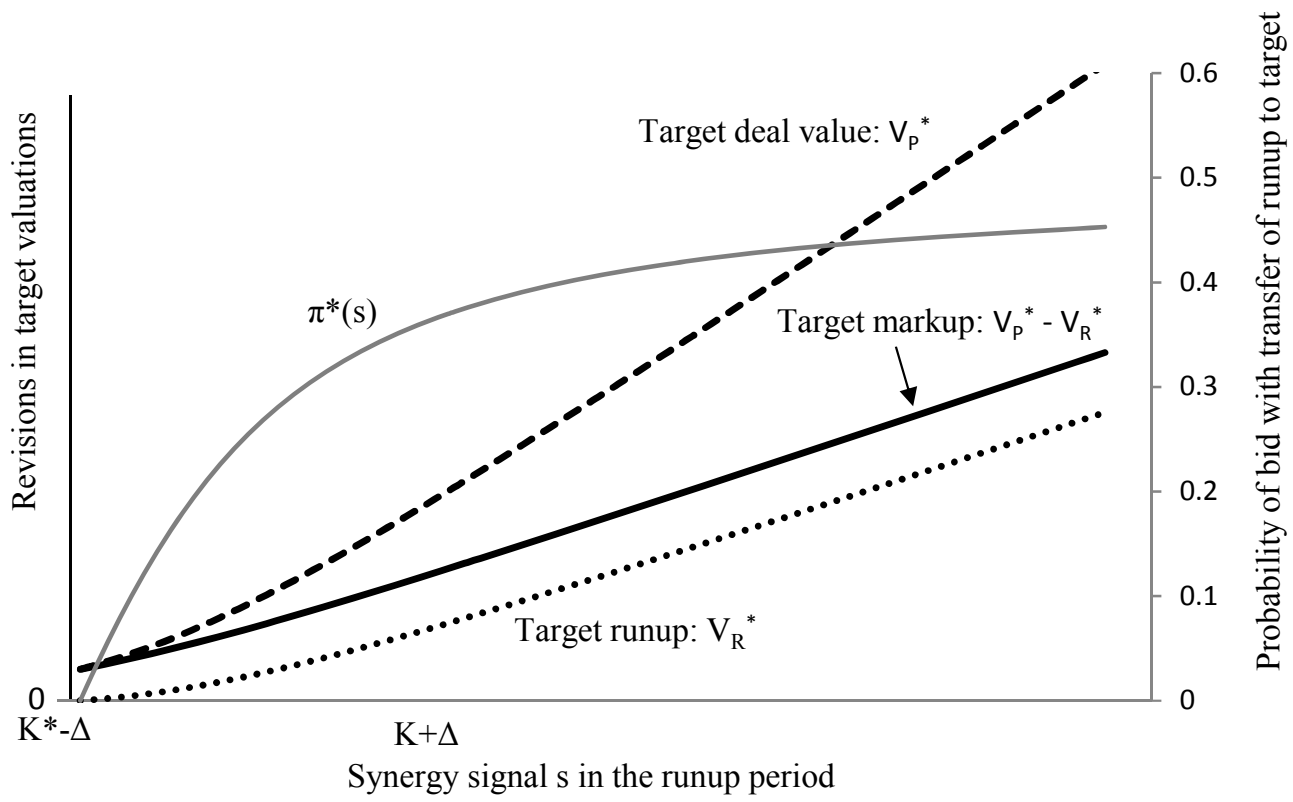

Panel B: Projection of $\mathrm{V}_{\mathrm{p}} * \mathrm{~V}_{\mathrm{R}} *$ on $\mathrm{V}_{\mathrm{R}} *$ with transfer of runup to target

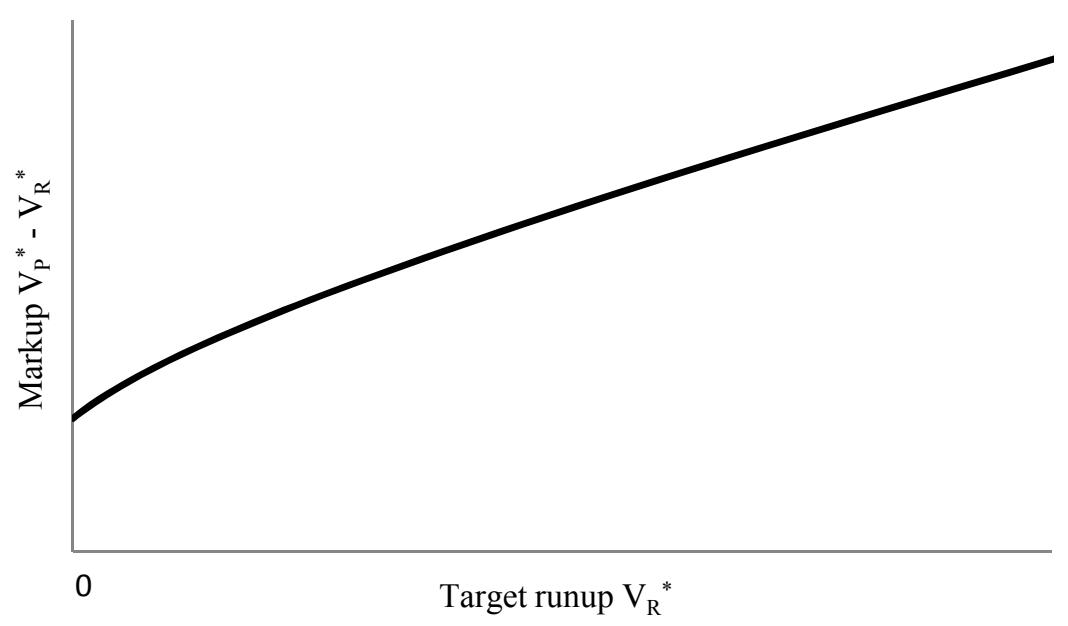

Figure 3. Target valuations and markup projection with costly feedback loop This figure plots target valuations (Panel A) and markup projection (Panel B) with costly feedback loop. The market receives a signal $s$ (horizontal axis in Panel A) about a potential takeover with synergy $S$, where $S \mid s \sim U(s-\Delta, s+\Delta$ ) and $\Delta=4$. The synergy sharing rule is $\theta=0.5$, and bid costs are $C=0.5$ (paid here by the bidder). The bidder raises the offer price by the target runup $V_{R}^{*}$ (a costly feedback loop), which lowers the takeover probability $\pi^{*}$ relative to $\pi$ in Figure 2 . $\pi^{*}$ (the right-side vertical axis of Panel A) converges to $\theta$. Panel B shows the corresponding markup projection (see the Appendix for the functional forms). 
Panel A: Markup projection using total runup

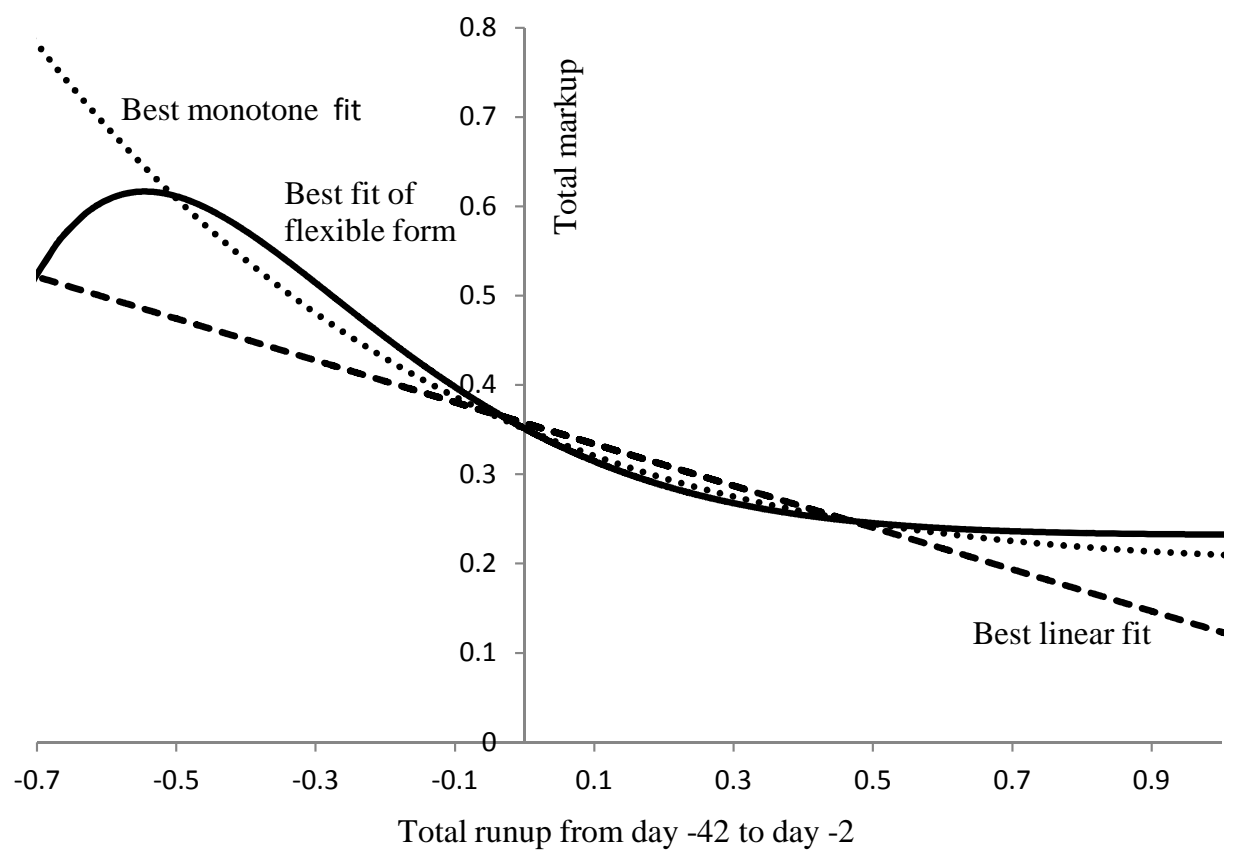

Panel B: Markup projection using runup adjusted for target stand-alone value change

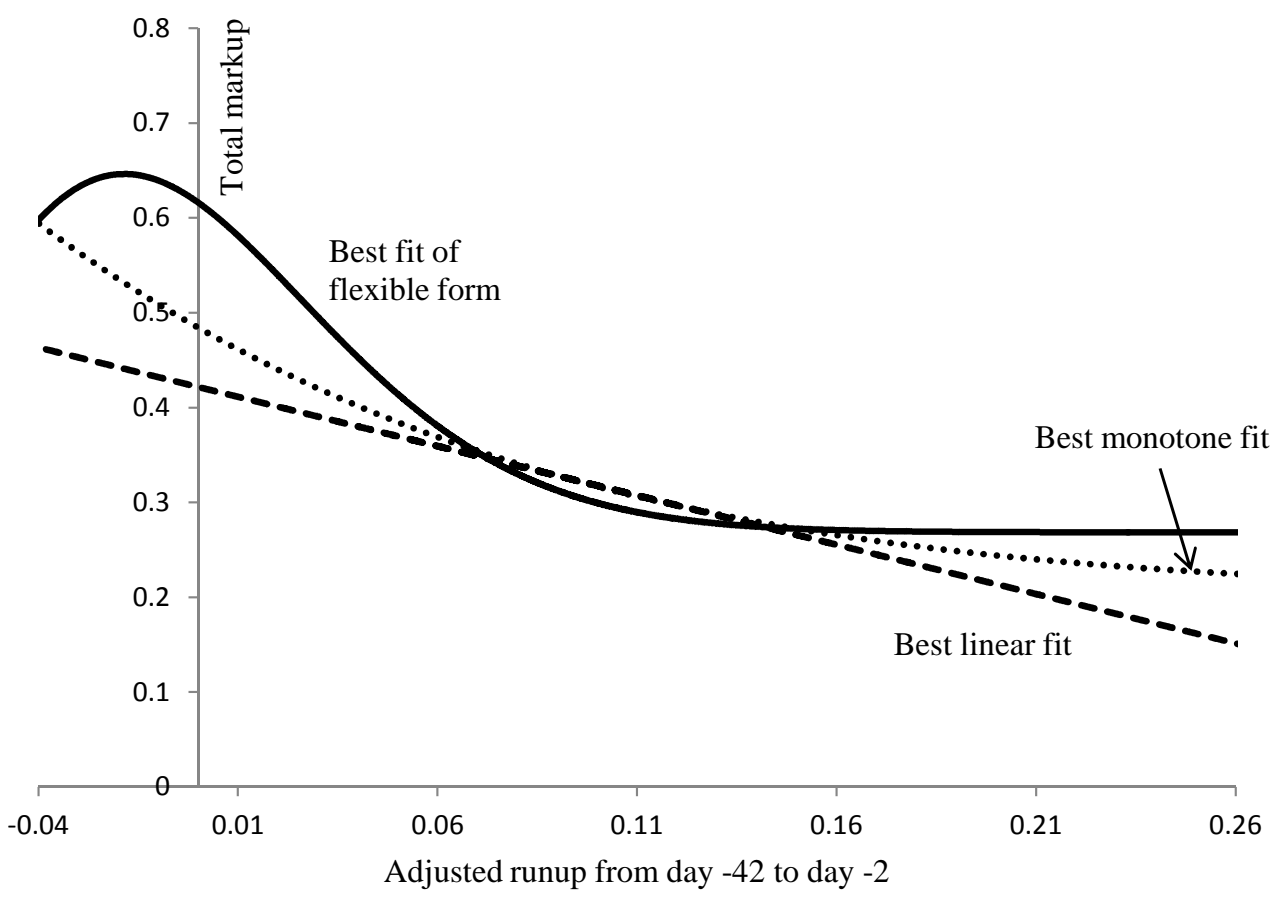

Figure 4. Markup projections estimated using offer prices. This figure plots markup projections estimated using offer prices. The total markup is $\left(O P / P_{-2}\right)-1$, where $O P$ is the offer price and $P_{-2}$ is the target closing price on day -2 relative to the first offer announcement date (day 0). In Panel A, the total runup is $\left(P_{-2} / P_{-42}\right)-1$. In Panel B, the adjusted runup is the total runup in Panel A minus the BLUE estimate (equation (19)) of the target's stand-alone value change $T$ over the runup period. For expositional purposes, Panel B plots the functions using the middle $98 \%$ of the adjusted runups. All forms are estimated using the beta function, equation (17). The sample comprises 6,146 bids over the 1980 to 2008 period. 


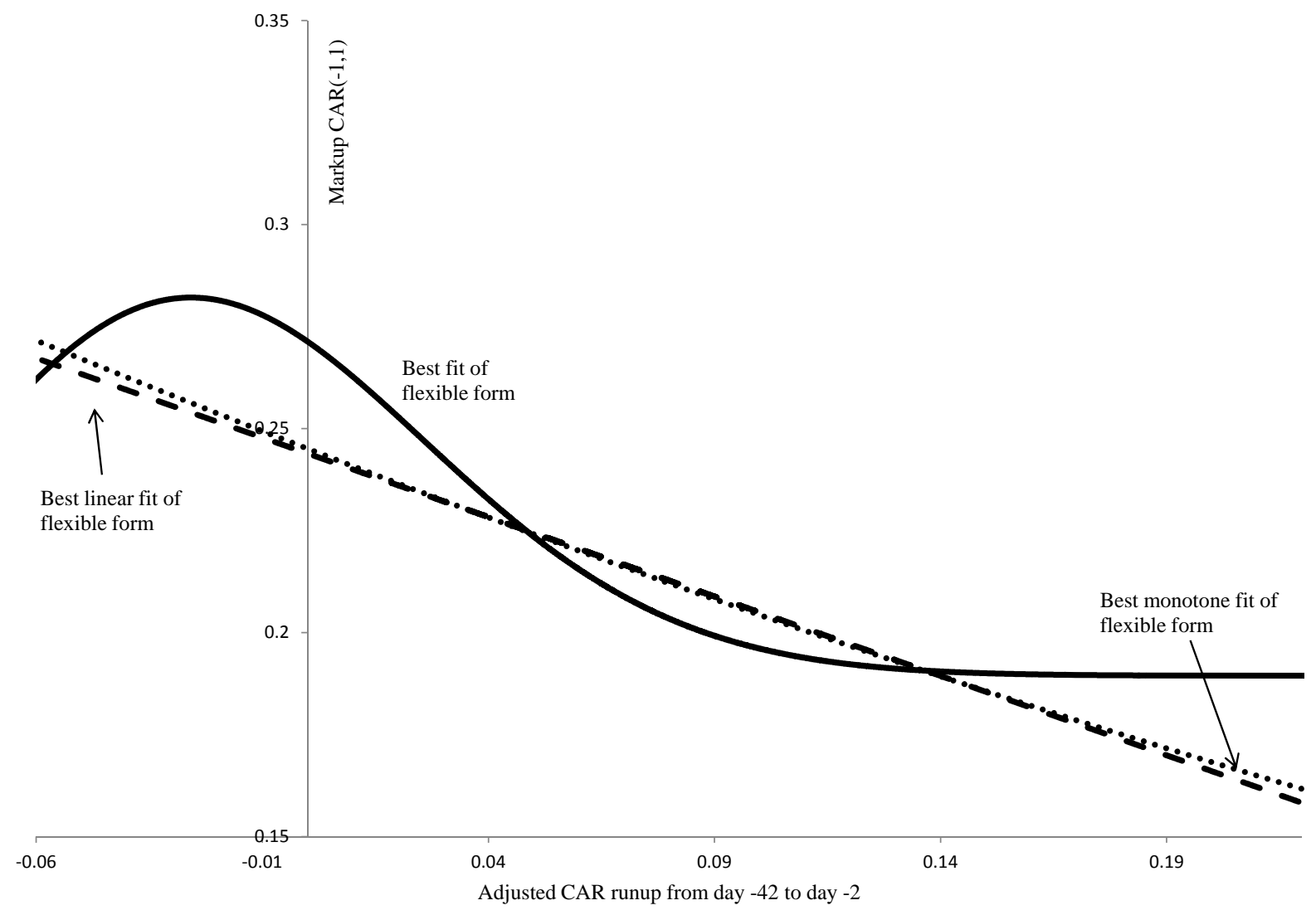

Figure 5. Markup projection estimated using target cumulative abnormal returns (CAR). This figure plots the markup projection estimated using target CAR. The markup is target CAR $(-1,1)$ relative to the day of the first offer announcement (day 0). The runup is $\operatorname{CAR}(-41,-2)$ adjusted for the target's stand-alone value change $T$ over the runup period, using the BLUE estimator in equation (19). Abnormal stock returns are estimated using the market model. For expositional purposes, the figure plots the functions over the middle $98 \%$ of the adjusted runups. All forms are estimated using the beta function, equation (17). The sample comprises 6,146 bids over the 1980 to 2008 period. 
Panel A: Total bidder gains on target CAR runups

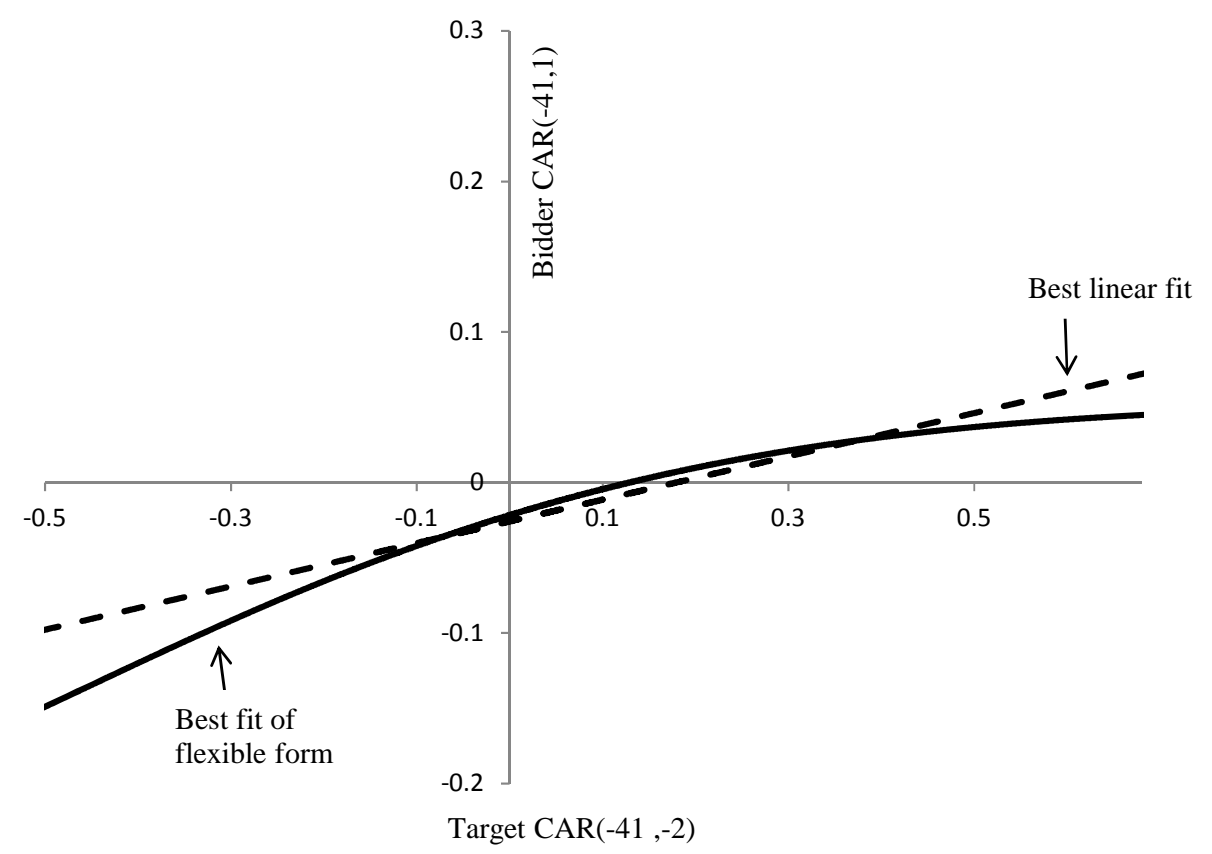

Panel B: Total bidder gains on adjusted target CAR runups

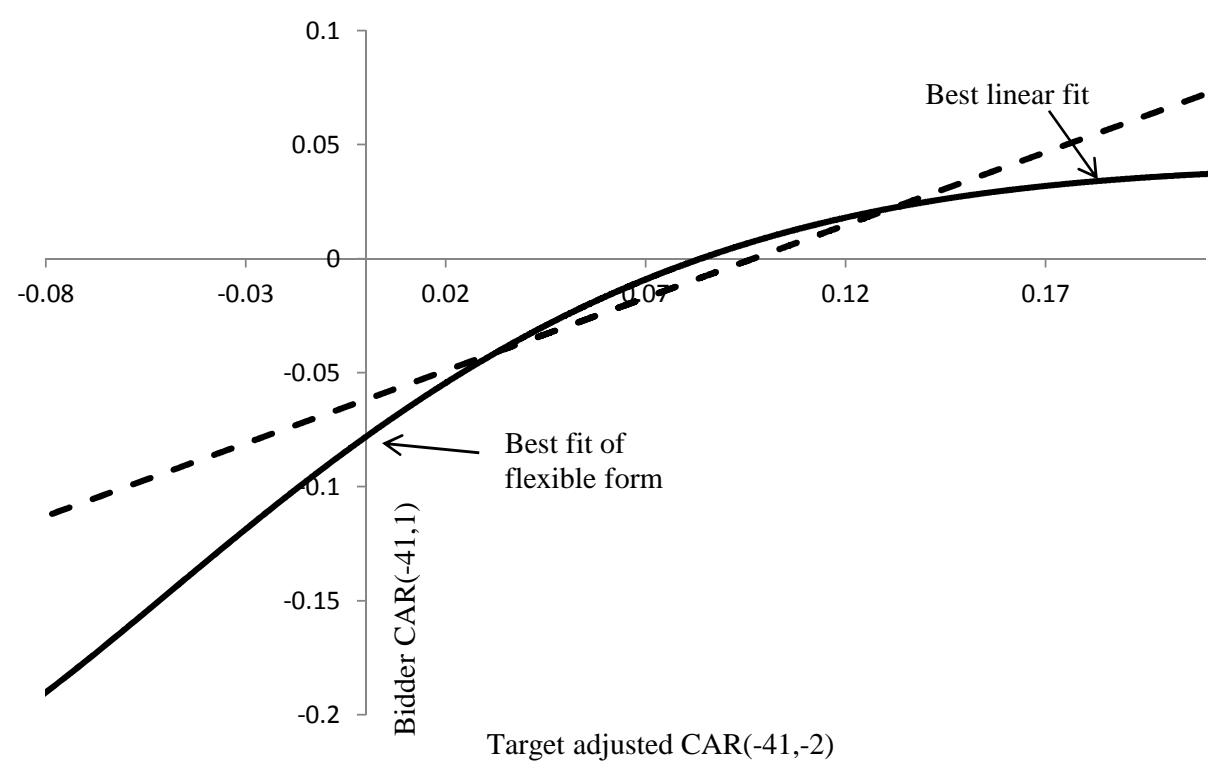

Figure 6. Projections of total bidder gains on target runups using CAR. This figure plots projections of bidder gains on target runups using CAR. Bidder takeover gains are bidder cumulative abnormal stock returns from the beginning of the runup period and through the day after the bid announcement, BCAR(-41,1). The target runup is the target CAR(-41,-2). Abnormal returns are estimated using the market model, while the forms shown in the figure are estimated using equation (17). For expositional purposes, the figure plots the functions over the middle $98 \%$ of the adjusted runups. A likelihood ratio (goodness-of-fit) test rejects linearity in favor of the nonlinear form in the data. The sample comprises 3,689 public bidders over the 1980 to 2008 period. 


\section{Table I}

\section{Summary of Theoretical Predictions and Empirical Tests}

This table provides a summary of the theoretical predictions and empirical tests of Propositions 1 to 3 . $V_{P}$ is the market's valuation of the target synergy gains $B$ conditional on the takeover bid (the target deal value), $V_{R}$ is the target runup, $V_{P}-V_{R}$ is the offer markup, and $A$ is the bidder synergy gains net of bidding costs. For convenience, $V_{R}$ and $V_{P}$ are used to denote both the theoretical and the empirical values (although only the empirical values may include a target stand-alone value change during the runup period). $\Lambda\left(V_{R}\right)$ is a nonlinear transformation of $V_{R}$ using the beta function (equation (17)). The cross-sectional estimation also includes a number of control variables not shown here (defined in Table V).

Economic model

Econometric model

Empirical Tests

Proposition 1: Markup projection with rational deal anticipation and no feedback loop

$V_{P}-V_{R}=\frac{1-\pi}{\pi} V_{R} \quad V_{P}-V_{R}=a+b \Lambda\left(V_{R}\right)+e \quad$ Linear slope $b$ strictly greater than -1

Goodness-of-fit tests for nonlinearity

Correction of $V_{R}$ for a change in target's stand-alone value $T$

Proposition 2: Markup projection with rational deal anticipation and costly feedback loop

$V_{P}^{*}-V_{R}^{*}=E^{*}(B(S) \mid s, b i d) \quad V_{P}-V_{R}=a+b V_{R}+e \quad$ Slope $b$ is positive everywhere: $b>0$

Proposition 3: Deal anticipation and relation between bidder and target gains

$\begin{array}{ll}\operatorname{Cov}(A, B)>0 & b>0, \text { where } \nu_{P} \text { is an estimate of } A \\ \operatorname{Cov}\left(A, V_{R}\right)>0 & b>0 \\ \nu_{P}=a+b V_{R}+e & b=0 \text { if } d V_{P} / d s=0 \text { and no costly feedback loop } \\ & b<0 \text { if } d V_{P} / d s=0 \text { with costly feedback loop }\end{array}$

\section{Auxiliary hypotheses - effects of shocks to target runup on offer premium}

Toehold purchases are costly $\quad V_{R}=a+b \alpha+e$

Toehold purchase of $\alpha$ fuels runup: $b>0$

$V_{P}=a+b V_{R}+c \alpha+e$

Costly feedback: $b, c>0$

Pass-through of market return $V_{P}=a+b\left(V_{R}-R_{M}\right)+c R_{M}+e \quad b, c>0$, where $R_{M}$ is market return 
Table II

\section{Sample Selection}

This table provides a description of the sample selection process. An initial bid is the first control bid for the target in 126 trading days (six months). Bids are grouped into takeover contests, which end when there are no new control bids for the target in 126 trading days. All stock prices $p_{i}$ are adjusted for splits and dividends, where $i$ is the trading day relative to the announcement date (day 0 ).

\begin{tabular}{|c|c|c|c|}
\hline Selection criteria & Source & $\begin{array}{l}\text { Number of } \\
\text { exclusions }\end{array}$ & $\begin{array}{c}\text { Sample } \\
\text { size }\end{array}$ \\
\hline $\begin{array}{l}\text { All initial control bids in SDC }(\mathrm{FORMC}=\mathrm{M}, \mathrm{AM}) \text { for U.S. public targets } \\
\text { during the period } 1 / 1980 \text { to } 12 / 2008\end{array}$ & $\mathrm{SDC}$ & & 13,893 \\
\hline Bidder owns $<50 \%$ of the target shares at the time of the bid & $\mathrm{SDC}$ & 46 & 13,847 \\
\hline $\begin{array}{l}\text { Target firm has at least } 100 \text { days of common stock returns } \\
\text { in CRSP over the estimation period (day }-297 \text { to -43) } \\
\text { and is listed on NYSE, Amex, or NASDAQ }\end{array}$ & CRSP & 4,138 & 9,109 \\
\hline Deal value $>\$ 10$ million & $\mathrm{SDC}$ & 1,816 & 7,293 \\
\hline Target stock price on day $-42>\$ 1$ & CRSP & 191 & 7,102 \\
\hline Offer price available & $\mathrm{SDC}$ & 239 & 6,863 \\
\hline Target stock price on day -2 available & CRSP & 6 & 6,857 \\
\hline Target announcement returns $[-1,1]$ available & CRSP & 119 & 6,738 \\
\hline Information on outcome and ending date of contest available & $\mathrm{SDC}$ & 324 & 6,414 \\
\hline Contest shorter than 252 trading days & $\mathrm{SDC}$ & 264 & 6,150 \\
\hline
\end{tabular}


Table III

Annual Distribution of the Initial Offer Premium, Total Markup, and Total Runup

This table shows the mean and median offer premium, markup, target stock price runup and net runup for the sample of 6,150 initial control bids for U.S. publicly traded target firms over the 1980 to 2008 period. The premium is $\left(O P / P_{-42}\right)-1$, where $O P$ is the price per share offered by the initial control bidder and $P_{i}$ is the target stock price on trading day $i$ relative to the takeover announcement date $(i=0)$, adjusted for splits and dividends. The total markup is $\left(O P / P_{-2}\right)-1$, the total runup is $\left(P_{-2} / P_{-42}\right)-1$, and the net runup is $\left(P_{-2} / P_{-42}\right)-\left(M_{-2} / M_{-42}\right)$, where $M_{i}$ is the value of the equal-weighted market portfolio on day $i$.

\begin{tabular}{|c|c|c|c|c|c|c|c|c|c|}
\hline \multirow[b]{2}{*}{ Year } & \multirow{2}{*}{$\begin{array}{c}\text { Sample } \\
\text { size }\end{array}$} & \multicolumn{2}{|c|}{$\begin{array}{l}\text { Offer premium } \\
\frac{O P}{P_{-42}}-1\end{array}$} & \multicolumn{2}{|c|}{$\begin{array}{l}\text { Total markup } \\
\qquad \frac{O P}{P_{-2}}-1 \\
\end{array}$} & \multicolumn{2}{|c|}{$\begin{array}{l}\text { Total runup } \\
\frac{P_{-2}}{P_{-42}}-1\end{array}$} & \multicolumn{2}{|c|}{$\begin{array}{c}\text { Net runup } \\
\frac{P_{-2}}{P_{-42}}-\frac{M_{-2}}{M_{-42}} \\
\end{array}$} \\
\hline & & mean & median & mean & median & mean & median & mean & \\
\hline 1980 & 10 & 0.70 & 0.69 & 0.53 & 0.34 & 0.15 & 0.19 & 0.10 & 0.12 \\
\hline 1981 & 35 & 0.60 & 0.48 & 0.40 & 0.36 & 0.15 & 0.13 & 0.16 & 0.14 \\
\hline 1982 & 48 & 0.53 & 0.48 & 0.34 & 0.32 & 0.15 & 0.10 & 0.13 & 0.09 \\
\hline 1983 & 58 & 0.49 & 0.50 & 0.33 & 0.35 & 0.12 & 0.12 & 0.10 & 0.08 \\
\hline 1984 & 115 & 0.51 & 0.43 & 0.45 & 0.32 & 0.07 & 0.05 & 0.06 & 0.06 \\
\hline 1985 & 161 & 0.40 & 0.34 & 0.26 & 0.22 & 0.11 & 0.10 & 0.08 & 0.06 \\
\hline 1986 & 209 & 0.40 & 0.36 & 0.26 & 0.23 & 0.12 & 0.09 & 0.08 & 0.06 \\
\hline 1987 & 202 & 0.39 & 0.36 & 0.32 & 0.25 & 0.07 & 0.07 & 0.06 & 0.03 \\
\hline 1988 & 270 & 0.56 & 0.47 & 0.35 & 0.29 & 0.15 & 0.10 & 0.12 & 0.08 \\
\hline 1989 & 194 & 0.54 & 0.43 & 0.39 & 0.30 & 0.11 & 0.07 & 0.07 & 0.03 \\
\hline 1990 & 103 & 0.53 & 0.49 & 0.49 & 0.41 & 0.05 & -0.00 & 0.05 & -0.01 \\
\hline 1991 & 91 & 0.55 & 0.46 & 0.40 & 0.33 & 0.12 & 0.09 & 0.08 & 0.05 \\
\hline 1992 & 106 & 0.57 & 0.51 & 0.40 & 0.35 & 0.13 & 0.08 & 0.11 & 0.08 \\
\hline 1993 & 146 & 0.48 & 0.43 & 0.36 & 0.33 & 0.10 & 0.07 & 0.08 & 0.05 \\
\hline 1994 & 228 & 0.44 & 0.42 & 0.34 & 0.31 & 0.08 & 0.07 & 0.07 & 0.07 \\
\hline 1995 & 290 & 0.47 & 0.39 & 0.33 & 0.27 & 0.11 & 0.09 & 0.06 & 0.04 \\
\hline 1996 & 319 & 0.40 & 0.37 & 0.27 & 0.24 & 0.11 & 0.07 & 0.07 & 0.04 \\
\hline 1997 & 434 & 0.41 & 0.38 & 0.26 & 0.23 & 0.13 & 0.12 & 0.09 & 0.08 \\
\hline 1998 & 465 & 0.46 & 0.37 & 0.37 & 0.26 & 0.08 & 0.07 & 0.05 & 0.03 \\
\hline 1999 & 496 & 0.55 & 0.45 & 0.37 & 0.30 & 0.15 & 0.11 & 0.12 & 0.08 \\
\hline 2000 & 415 & 0.53 & 0.45 & 0.38 & 0.34 & 0.13 & 0.06 & 0.12 & 0.08 \\
\hline 2001 & 270 & 0.55 & 0.46 & 0.40 & 0.34 & 0.11 & 0.08 & 0.12 & 0.09 \\
\hline 2002 & 154 & 0.52 & 0.36 & 0.42 & 0.32 & 0.09 & 0.03 & 0.12 & 0.06 \\
\hline 2003 & 189 & 0.47 & 0.34 & 0.30 & 0.23 & 0.13 & 0.08 & 0.09 & 0.05 \\
\hline 2004 & 195 & 0.30 & 0.26 & 0.24 & 0.21 & 0.06 & 0.04 & 0.03 & 0.02 \\
\hline 2005 & 230 & 0.30 & 0.27 & 0.25 & 0.21 & 0.05 & 0.04 & 0.04 & 0.03 \\
\hline 2006 & 258 & 0.31 & 0.27 & 0.25 & 0.21 & 0.05 & 0.03 & 0.03 & 0.02 \\
\hline 2007 & 284 & 0.31 & 0.28 & 0.29 & 0.23 & 0.02 & 0.02 & 0.00 & 0.00 \\
\hline 2008 & 175 & 0.34 & 0.30 & 0.40 & 0.34 & -0.04 & -0.04 & 0.01 & 0.00 \\
\hline Total & 6,150 & 0.45 & 0.38 & 0.33 & 0.27 & 0.10 & 0.07 & 0.08 & 0.05 \\
\hline
\end{tabular}




\section{Table IV \\ Empirical Projections of Markups on Runups}

This table shows the coefficient estimates in empirical projections of markups on runups. $V_{R j}$ is the runup and $V_{P j}-V_{R j}$ is the markup of the $j^{\prime} t h$ target. The projection is

$$
V_{P j}-V_{R j}=a+b \frac{\left(V_{R j}-\min \right)^{(v-1)}\left(\max -V_{R j}\right)^{w-1}}{\Lambda(v, w)(\max -\min )^{v+w-1}}+\epsilon_{j}, \quad j=1, \ldots, N
$$

where $\Lambda(v, w)$ is the beta distribution with shape parameters $v$ and $w$, max and min are the maximum and minimum $V_{R}$ in the data, respectively, $a$ is an overall intercept, $b$ is a scale parameter, and $\epsilon_{j}$ is a residual error term. When constraining the shape to be linear, the projection delivers OLS estimates of $a$ and $b$, which are reported below. The reported $t$-statistics are for $b=0$. LR is the likelihood ratio test statistic, distributed $\chi^{2}(d)$. $L R 1$ tests nonlinearity against linearity $(d=2,1 \%$ critical value 9.2$) . L R 2$ tests monotonicity against linearity ( $d=1$, critical value 6.6$) . L R 3 \equiv L R 1-L R 2$ tests nonlinearity against monotonicity $(d=1$, critical value 6.6$)$. The sample comprises 6,150 initial control bids for U.S. public targets over the 1980 to 2008 period.

\begin{tabular}{|c|c|c|c|c|c|c|}
\hline & $\begin{array}{c}\text { Markup measure } \\
V_{P}-V_{R} \\
\end{array}$ & $\begin{array}{c}\text { Runup measure } \\
V_{R} \\
\end{array}$ & Linear projection & $L R 1$ & $L R 2$ & LR3 \\
\hline $\begin{array}{l}\text { (1) } \\
\mathrm{N}=6,150\end{array}$ & $\begin{array}{l}\text { Total markup } \\
\quad \frac{O P}{P_{-2}}-1\end{array}$ & $\begin{array}{l}\text { Total runup } \\
\frac{P-2}{P_{-42}}-1\end{array}$ & $\begin{array}{c}a=0.36 \\
b=-0.24(t=-11.9)\end{array}$ & $\begin{array}{c}98.1 \\
(\mathrm{p}<0.001)\end{array}$ & $\begin{array}{c}38.4 \\
(\mathrm{p}<0.001)\end{array}$ & $\begin{array}{c}59.7 \\
(\mathrm{p}<0.001)\end{array}$ \\
\hline $\begin{array}{l}(2) \\
\mathrm{N}=6,146\end{array}$ & $\begin{array}{l}\text { Total markup } \\
\quad \frac{O P}{P_{-2}}-1\end{array}$ & $\begin{array}{c}\text { Adjusted runup }^{a} \\
(1-\beta) V_{R}+\beta E\left(V_{R}\right)\end{array}$ & $\begin{array}{c}a=0.43 \\
b=-1.01(t=-11.9)\end{array}$ & $\begin{array}{c}125.6 \\
(\mathrm{p}<0.001)\end{array}$ & $\begin{array}{c}64.5 \\
(\mathrm{p}<0.001)\end{array}$ & $\begin{array}{c}61.1 \\
(\mathrm{p}<0.001)\end{array}$ \\
\hline $\begin{array}{l}(3) \\
\mathrm{N}=6,150\end{array}$ & $\begin{array}{l}\text { Market model } \\
C A R(-1,1)\end{array}$ & $\begin{array}{l}\text { Market model } \\
C A R(-41,-2)\end{array}$ & $\begin{array}{c}a=0.22 \\
b=-0.09(t=-6.7)\end{array}$ & $\begin{array}{c}18.6 \\
(\mathrm{p}<0.001)\end{array}$ & $\begin{array}{c}16.8 \\
(\mathrm{p}<0.001)\end{array}$ & $\begin{array}{c}1.8 \\
(\mathrm{p}=0.180)\end{array}$ \\
\hline $\begin{array}{l}\text { (4) } \\
\mathrm{N}=6,146\end{array}$ & $\begin{array}{l}\text { Market Model }^{b} \\
C A R(-1,1)\end{array}$ & $\begin{array}{l}\text { Adjusted runup } \\
C A R(-41,-2)\end{array}$ & $\begin{array}{c}a=0.24 \\
b=-0.39(t=-6.7)\end{array}$ & $\begin{array}{c}33.3 \\
(\mathrm{p}<0.001)\end{array}$ & $\begin{array}{c}32.68 \\
(\mathrm{p}<0.001)\end{array}$ & $\begin{array}{c}0.8 \\
(\mathrm{p}=0.377)\end{array}$ \\
\hline $\begin{array}{l}(5) \\
\mathrm{N}=6,103\end{array}$ & $\begin{array}{c}\text { Expected markup }{ }^{c} \\
\pi\left(\frac{O P}{P_{-2}}-1\right)\end{array}$ & $\begin{array}{l}\text { Total runup } \\
\frac{P_{-2}}{P_{-42}}-1\end{array}$ & $\begin{array}{c}a=0.31 \\
b=-0.17(t=-9.5)\end{array}$ & $\begin{array}{c}137.1 \\
(\mathrm{p}<0.001)\end{array}$ & $\begin{array}{c}62.2 \\
(\mathrm{p}<0.001)\end{array}$ & $\begin{array}{c}74.9 \\
(\mathrm{p}<0.001)\end{array}$ \\
\hline $\begin{array}{l}(6) \\
\mathrm{N}=6,099\end{array}$ & $\begin{array}{l}\text { Expected markup }{ }^{c} \\
\quad \pi\left(\frac{O P}{P_{-2}}-1\right)\end{array}$ & $\begin{array}{c}\text { Adjusted runup }^{a} \\
(1-\beta) V_{R}+\beta E\left(V_{R}\right)\end{array}$ & $\begin{array}{c}a=0.36 \\
b=-0.75(t=-9.4)\end{array}$ & $\begin{array}{c}194.0 \\
(\mathrm{p}<0.001)\end{array}$ & $\begin{array}{c}123.6 \\
(\mathrm{p}<0.001)\end{array}$ & $\begin{array}{c}70.4 \\
(\mathrm{p}<0.001)\end{array}$ \\
\hline $\begin{array}{l}(7) \\
\mathrm{N}=6,099\end{array}$ & $\begin{array}{l}\text { Residual markup }^{d} \\
U_{P}\end{array}$ & $\begin{array}{l}\text { Augmented runup } \\
\left(\frac{P_{-2}}{P_{-42}}-1\right)+R_{0}\end{array}$ & $\begin{array}{c}a=0.36 \\
b=-0.26(t=-12.1)\end{array}$ & $\begin{array}{c}225.9 \\
(\mathrm{p}<0.001)\end{array}$ & $\begin{array}{c}89.8 \\
(\mathrm{p}<0.001)\end{array}$ & $\begin{array}{c}136.1 \\
(\mathrm{p}<0.001)\end{array}$ \\
\hline
\end{tabular}

${ }^{a}$ This projection uses the runup adjusted for the cross-sectional variation in target stand-alone value (equation (21) in the text). $V_{R}$ is the total runup in model (1), and the average $\beta$ used to adjust $V_{R}$ is 0.77 , with a max (min) of $0.99(0.74)$. See the text for details of the estimation of adjustment parameter $\beta$.

$b$ Target CAR are computed using the estimated market model parameters: $r_{i t}=\alpha_{i}+\beta_{i} r_{m t}+u_{i t}$, where $r_{i t}$ and $r_{m t}$ are the daily returns on stock $i$ and the value-weighted market portfolio, and $u_{i t}$ is a residual error term. The estimation period is from day -297 to day -43 relative to the day of the announcement of the initial bid.

${ }^{c}$ This projection is for the subsample with available data on the target, bidder and deal characteristics used to estimate the probability $\pi$ of bid success in Table VI. The projection includes the effect of these variables by multiplying the total markup by the estimated value of $\pi$.

${ }^{d}$ Residual markup, $U_{P}$, is the residual from the projection of the total markup, $\frac{O P}{P_{-2}}-1$, on the deal characteristics used to estimate the success probability $\pi$ in Table VI, excluding Positive toehold, Toehold size, and 52-week high, which are used to construct the augmented runup. Variable definitions are in Table V.

$e$ The enhancement $R_{0}$ in the augmented runup adds back to the runup the effect of information that the market might use to anticipate possible takeover activity prior to the runup period. $R_{0}$ is the projection of the total runup $\left(\frac{P_{-2}}{P_{-42}}-1\right)$ on the deal characteristics Positive toehold, Toehold size, and the negative value of 52-week high, all of which may affect the prior probability of a takeover (prior to the runup period). The augmented runup is the total runup plus $R_{0}$. Variable definitions are in Table V. 


\section{Table V \\ Variable Definitions}

This table provides definitions of the variables used in the analyses. All stock prices $P_{i}$ are adjusted for splits and dividends, where $i$ is the trading day relative to the date of announcement $(i=0)$, and, if missing, replaced by the midpoint of the bid-ask spread.

\begin{tabular}{lll}
\hline Variable & Definition & Source \\
\hline
\end{tabular}

\section{Target characteristics}

Target size Natural logarithm of the target market capitalization in $\$$ billion on day -42 CRSP

Relative size Ratio of target market capitalization to bidder market capitalization on day -42 CRSP

NYSE/Amex The target is listed on NYSE or Amex vs. NASDAQ (dummy) CRSP

Turnover Average daily ratio of trading volume to total shares outstanding over the 52 CRSP weeks ending on day -43

Poison pill The target has a poison pill (dummy)

SDC

52-week high Change in the target stock price from the highest price $P_{\text {high }}$ over the 52 weeks CRSP ending on day $-43, P_{-42} / P_{\text {high }}-1$

\section{Bidder characteristics}

Toehold

Toehold size

Stake bidder

Stake other

Acquirer public

Horizontal

$>20 \%$ new equity
The acquirer owns shares in the target when announcing the bid (dummy)

SDC

Percent target shares owned by the acquirer when announcing the bid

SDC

The initial bidder buys a small equity stake in the target during the runup SDC period through day 0 (dummy)

Another investor buys a small equity stake in the target during the runup period SDC through day 0 (dummy)

The acquirer is publicly traded (dummy)

SDC

The bidder and the target have the same primary four-digit SIC code (dummy) SDC

Consideration includes a stock portion that exceeds $20 \%$ of the acquirer's shares SDC outstanding (dummy)

\section{Contest characteristics}

Premium

Bid premium defined as $\left(O P / P_{-42}\right)-1$, where $O P$ is the offer price

Net runup

Target net runup defined as $\left(P_{-2} / P_{-42}\right)-\left(M_{-2} / M_{-42}\right)$, where $M_{i}$ is the value of the equal-weighted market portfolio on day $i$

Market runup Stock market return during the runup period defined as $M_{-2} / M_{-42}-1$, where CRSP $M_{i}$ is the value of the equal-weighted market portfolio on day $i$

Whitened net runup The unstandardized residuals from a regression of the target net runup on mar- CRSP ket runup

Tender offer The initial bid is a tender offer (dummy)

All cash Consideration is cash only (dummy)

All stock Consideration is stock only (dummy)

Hostile Target management's response is hostile vs. friendly or neutral (dummy) 


\section{Table VI}

\section{Logit Estimations of the Conditional Bid Success Probability}

This table reports the parameter estimates in logit regressions for the probability that the contest is successful (columns (1) and (2)), and for the probability that the initial control bidder wins (columns (3) to (6)). All variable definitions are in Table $\mathrm{V}$ ( $p$-values in parentheses). The sample comprises 6,103 initial control bids for public U.S. targets with a complete set of control variables over the 1980 to 2008 period.

\begin{tabular}{|c|c|c|c|c|c|c|}
\hline \multirow[t]{2}{*}{ Dependent variable: } & \multicolumn{2}{|c|}{ Contest successful } & \multicolumn{4}{|c|}{ Initial control bidder wins } \\
\hline & (1) & $(2)$ & (3) & (4) & (5) & $(6)$ \\
\hline Intercept & $\begin{array}{c}1.047 \\
(<0.001)\end{array}$ & $\begin{array}{c}0.909 \\
(<0.001)\end{array}$ & $\begin{array}{c}0.657 \\
(<0.001)\end{array}$ & $\begin{array}{c}0.455 \\
(0.005)\end{array}$ & $\begin{array}{c}0.626 \\
(<0.001)\end{array}$ & $\begin{array}{c}0.437 \\
(0.007)\end{array}$ \\
\hline \multicolumn{7}{|l|}{ Target characteristics } \\
\hline Target size & $\begin{array}{c}0.137 \\
(<0.001)\end{array}$ & $\begin{array}{c}0.085 \\
(0.005)\end{array}$ & $\begin{array}{c}0.148 \\
(<0.001)\end{array}$ & $\begin{array}{c}0.094 \\
(0.001)\end{array}$ & $\begin{array}{c}0.150 \\
(<0.001)\end{array}$ & $\begin{array}{c}0.096 \\
(0.001)\end{array}$ \\
\hline NYSE/Amex & $\begin{array}{c}-0.365 \\
(<0.001)\end{array}$ & $\begin{array}{l}-0.269 \\
(0.005)\end{array}$ & $\begin{array}{c}-0.435 \\
(<0.001)\end{array}$ & $\begin{array}{l}-0.330 \\
(<0.001)\end{array}$ & $\begin{array}{c}-0.433 \\
(<0.001)\end{array}$ & $\begin{array}{c}-0.329 \\
(<0.001)\end{array}$ \\
\hline Turnover & $\begin{array}{l}-0.017 \\
(0.002)\end{array}$ & $\begin{array}{l}-0.019 \\
(0.001)\end{array}$ & $\begin{array}{l}-0.017 \\
(0.002)\end{array}$ & $\begin{array}{l}-0.019 \\
(0.001)\end{array}$ & $\begin{array}{l}-0.017 \\
(0.003)\end{array}$ & $\begin{array}{r}-0.019 \\
(0.001)\end{array}$ \\
\hline Poison pill & $\begin{array}{l}-0.578 \\
(0.028)\end{array}$ & $\begin{array}{l}-0.513 \\
(0.053)\end{array}$ & $\begin{array}{l}-0.506 \\
(0.063)\end{array}$ & $\begin{array}{l}-0.436 \\
(0.114)\end{array}$ & $\begin{array}{c}-0.406 \\
(0.138)\end{array}$ & $\begin{array}{c}-0.341 \\
(0.219)\end{array}$ \\
\hline 52-week high & $\begin{array}{c}1.022 \\
(<0.001)\end{array}$ & $\begin{array}{c}1.255 \\
(<0.001)\end{array}$ & $\begin{array}{c}0.864 \\
(<0.001)\end{array}$ & $\begin{array}{c}1.117 \\
(<0.001)\end{array}$ & $\begin{array}{c}0.868 \\
(<0.001)\end{array}$ & $\begin{array}{c}1.120 \\
(<0.001)\end{array}$ \\
\hline \multicolumn{7}{|l|}{ Bidder characteristics } \\
\hline Toehold & $\begin{array}{l}-0.819 \\
(<0.001)\end{array}$ & $\begin{array}{c}-0.688 \\
(<0.001)\end{array}$ & $\begin{array}{c}-0.978 \\
(<0.001)\end{array}$ & $\begin{array}{c}-0.833 \\
(<0.001)\end{array}$ & $\begin{array}{c}-1.589 \\
(<0.001)\end{array}$ & $\begin{array}{c}-1.419 \\
(<0.001)\end{array}$ \\
\hline Toehold size & & & & & $\begin{array}{c}0.039 \\
(<0.001)\end{array}$ & $\begin{array}{c}0.038 \\
(<0.001)\end{array}$ \\
\hline Acquirer public & $\begin{array}{c}0.833 \\
(<0.001)\end{array}$ & $\begin{array}{c}0.804 \\
(<0.001)\end{array}$ & $\begin{array}{c}0.938 \\
(<0.001)\end{array}$ & $\begin{array}{c}0.900 \\
(<0.001)\end{array}$ & $\begin{array}{c}0.952 \\
(<0.001)\end{array}$ & $\begin{array}{c}0.915 \\
(<0.001)\end{array}$ \\
\hline Horizontal & $\begin{array}{c}0.248 \\
(0.020)\end{array}$ & $\begin{array}{c}0.211 \\
(0.050)\end{array}$ & $\begin{array}{c}0.276 \\
(0.006)\end{array}$ & $\begin{array}{c}0.226 \\
(0.025)\end{array}$ & $\begin{array}{c}0.281 \\
(0.005)\end{array}$ & $\begin{array}{c}0.232 \\
(0.022)\end{array}$ \\
\hline$>20 \%$ new equity & $\begin{array}{c}-0.585 \\
(<0.001)\end{array}$ & $\begin{array}{c}-0.577 \\
(<0.001)\end{array}$ & $\begin{array}{c}-0.531 \\
(<0.001)\end{array}$ & $\begin{array}{c}-0.522 \\
(<0.001)\end{array}$ & $\begin{array}{c}-0.536 \\
(<0.001)\end{array}$ & $\begin{array}{c}-0.526 \\
(<0.001)\end{array}$ \\
\hline Premium & $\begin{array}{c}0.343 \\
(0.001)\end{array}$ & $\begin{array}{c}0.371 \\
(<0.001)\end{array}$ & $\begin{array}{c}0.334 \\
(0.001)\end{array}$ & $\begin{array}{c}0.365 \\
(<0.001)\end{array}$ & $\begin{array}{c}0.350 \\
(<0.001)\end{array}$ & $\begin{array}{c}0.380 \\
(<0.001)\end{array}$ \\
\hline \multicolumn{7}{|l|}{ Deal characteristics } \\
\hline Tender offer & $\begin{array}{c}2.173 \\
(<0.001)\end{array}$ & $\begin{array}{c}2.307 \\
(<0.001)\end{array}$ & $\begin{array}{c}1.912 \\
(<0.001)\end{array}$ & $\begin{array}{c}2.053 \\
(<0.001)\end{array}$ & $\begin{array}{c}1.945 \\
(<0.001)\end{array}$ & $\begin{array}{c}2.085 \\
(<0.001)\end{array}$ \\
\hline All cash & $\begin{array}{l}-0.148 \\
(0.119)\end{array}$ & $\begin{array}{l}-0.276 \\
(0.005)\end{array}$ & $\begin{array}{l}-0.105 \\
(0.236)\end{array}$ & $\begin{array}{l}-0.224 \\
(0.014)\end{array}$ & $\begin{array}{l}-0.114 \\
(0.199)\end{array}$ & $\begin{array}{r}-0.236 \\
(0.010)\end{array}$ \\
\hline Hostile & $\begin{array}{c}-2.264 \\
(<0.001)\end{array}$ & $\begin{array}{c}-2.149 \\
(<0.001)\end{array}$ & $\begin{array}{c}-3.086 \\
(<0.001)\end{array}$ & $\begin{array}{c}-2.980 \\
(<0.001)\end{array}$ & $\begin{array}{c}-2.994 \\
(<0.001)\end{array}$ & $\begin{array}{c}-2.893 \\
(<0.001)\end{array}$ \\
\hline $1990 s$ & & $\begin{array}{c}0.435 \\
(<0.001)\end{array}$ & & $\begin{array}{c}0.566 \\
(<0.001)\end{array}$ & & $\begin{array}{c}0.548 \\
(<0.001)\end{array}$ \\
\hline $2000 s$ & & $\begin{array}{c}0.775 \\
(<0.001)\end{array}$ & & $\begin{array}{c}0.824 \\
(<0.001)\end{array}$ & & $\begin{array}{c}0.816 \\
(<0.001)\end{array}$ \\
\hline Pseudo- $R^{2}$ (Nagelkerke) & 0.208 & 0.219 & 0.263 & 0.276 & 0.269 & 0.281 \\
\hline$\chi^{2}$ & 755.1 & 795.8 & 1074.0 & 1129.3 & 1098.5 & 1151.8 \\
\hline
\end{tabular}




\section{Table VII}

\section{Regressions of Bidder Takeover Gains on Target Total Gains and Target Runup}

This table reports OLS parameter estimates in linear cross-sectional regressions with bidder CAR over trading days -41 to 1 as the dependent variable. CAR is estimated using the market model estimated over trading days -252 through -42 relative to the initial bid day. The variable Target $C A R(-41,1)$ is total target gains. The target runup is measured three ways: Target $C A R(-41,-2)$, Target adjusted $C A R(-41,-2)$ (adjusted for the BLUE estimator for target stand-alone value changes in equation (21) in the text), and Net target runup (computed as $\frac{P_{-2}}{P_{-42}}-\frac{M_{-2}}{M_{-42}}$, where $M$ is the value of the equal-weighted market portfolio. The $p$-values (in parentheses) use White's (1980) heteroskedasticity-consistent standard errors. The sample comprises 3,691 initial control bids by U.S. public bidders over the 1980 to 2008 period. The control variables are (i) target characteristics: Relative size, NYSE/Amex, and Turnover; (ii) bidder characteristics: Toehold size and Horizontal; and (iii) deal characteristics: All cash, All stock, and Hostile. See Table V for variable definitions.

\begin{tabular}{|c|c|c|c|c|c|c|}
\hline & \multicolumn{6}{|c|}{ Regression model } \\
\hline & (1) & $(2)$ & $(3)$ & (4) & $(5)$ & $(6)$ \\
\hline Intercept & $\begin{array}{c}-0.036 \\
(<0.001)\end{array}$ & $\begin{array}{c}-0.032 \\
(<0.001)\end{array}$ & $\begin{array}{c}-0.019 \\
(<0.001)\end{array}$ & $\begin{array}{l}-0.016 \\
(0.033)\end{array}$ & $\begin{array}{c}-0.052 \\
(<0.001)\end{array}$ & $\begin{array}{l}-0.010 \\
(0.209)\end{array}$ \\
\hline Target $C A R(-41,1)$ & $\begin{array}{c}0.101 \\
(<0.001)\end{array}$ & $\begin{array}{c}0.099 \\
(<0.001)\end{array}$ & & & & \\
\hline Target $C A R(-41,-2)$ & & & $\begin{array}{c}0.149 \\
(<0.001)\end{array}$ & $\begin{array}{c}0.147 \\
(<0.001)\end{array}$ & & \\
\hline Target adjusted $C A R(-41,-2)$ & & & & & $\begin{array}{c}0.649 \\
(<0.001)\end{array}$ & \\
\hline Net target runup & & & & & & $\begin{array}{c}0.079 \\
(<0.001)\end{array}$ \\
\hline 1999-2000 indicator & $\begin{array}{c}-0.041 \\
(<0.001)\end{array}$ & $\begin{array}{c}-0.036 \\
(<0.001)\end{array}$ & $\begin{array}{c}-0.039 \\
(<0.001)\end{array}$ & $\begin{array}{c}-0.034 \\
(<0.001)\end{array}$ & $\begin{array}{c}-0.034 \\
(<0.001)\end{array}$ & $\begin{array}{c}-0.032 \\
(<0.001)\end{array}$ \\
\hline Control variables & no & yes & no & yes & yes & yes \\
\hline Adjusted- $R^{2}$ & 0.036 & 0.056 & 0.040 & 0.061 & 0.062 & 0.038 \\
\hline F-value & $\begin{array}{c}41.6 \\
(<0.001)\end{array}$ & $\begin{array}{c}10.7 \\
(<0.001)\end{array}$ & $\begin{array}{c}39.6 \\
(<0.001)\end{array}$ & $\begin{array}{c}11.6 \\
(<0.001)\end{array}$ & $\begin{array}{c}11.7 \\
(<0.001)\end{array}$ & $\begin{array}{c}7.14 \\
(<0.001)\end{array}$ \\
\hline Sample size, $\mathrm{N}$ & 3,691 & 3,624 & 3,691 & 3,624 & 3,620 & 3,623 \\
\hline
\end{tabular}




\section{Table VIII}

\section{Description of Short-Term Toeholds Acquired by Bidders and Other Investors}

This table reports toehold acquisitions made by the initial control bidder, a rival control bidder, and other investors. Stake purchases are identified from records of completed partial acquisitions in SDC. The initial control bid is announced on day 0. The sample comprises 6,150 initial control bids for U.S. publicly traded targets over the 1980 to 2008 period.

Target stake announced in window $[-126,0] \quad[-42,0] \quad[-1,0]$
Total toehold on day 0

\section{Toehold acquired by initial control bidder}

Number of toehold purchases

Number of firms in which at least one stake is purchased

In percent of target firms

Size of toehold ( $\%$ of target shares) when toehold positive:

$\begin{array}{lcccc} & 136 & 104 & 70 & \\ & 122 & 94 & 63 & 648 \\ & 2.0 \% & 1.5 \% & 1.0 \% & 10.5 \% \\ \text { mean } & 12.2 \% & 11.7 \% & 12.7 \% & 15.5 \% \\ \text { median } & 9.9 \% & 9.3 \% & 9.4 \% & 9.9 \%\end{array}$

\section{Toehold acquired by rival control bidder}

Number of toehold purchases

Number of firms in which at least one stake is purchased

In percent of target firms

$\begin{array}{lcccc} & 7 & 3 & 1 & \\ & 6 & 3 & 1 & \\ & 0.1 \% & 0.05 \% & 0.02 \% & \mathrm{n} / \mathrm{a} \\ \text { mean } & 9.4 \% & 7.0 \% & 4.9 \% & \\ \text { median } & 9.1 \% & 6.2 \% & 4.9 \% & \end{array}$

\section{Toehold acquired by other investor}

Number of toehold purchases

$\begin{array}{lcccc} & 235 & 85 & 18 & \\ & 196 & 73 & 15 & \\ & 3.2 \% & 1.2 \% & 0.2 \% & \mathrm{n} / \mathrm{a} \\ \text { mean } & 6.8 \% & 8.7 \% & 10.1 \% & \\ \text { median } & 5.4 \% & 6.3 \% & 7.6 \% & \end{array}$


Table IX

Effects of Market Runup and Toehold Acquisition on Target Runup and Offer Premium

This table shows coefficient estimates in OLS regressions with target net runup (columns (1) and (2)) and offer premium (columns (3) to (6)) as dependent variables. All variable definitions are in Table V. The sample comprises 6,100 initial control bids for public U.S. targets with a complete set of control variables over the 1980 to 2008 period. ( $p$-values in parentheses).

\begin{tabular}{|c|c|c|c|c|c|c|}
\hline \multirow[t]{2}{*}{ Dependent variable: } & \multicolumn{2}{|c|}{$\begin{array}{l}\text { Target net runup } \\
\frac{P_{-2}}{P_{-42}}-\frac{M_{-2}}{M_{-42}}\end{array}$} & \multicolumn{4}{|c|}{$\begin{array}{l}\text { Offer premium } \\
\frac{O P}{P_{-42}}-1\end{array}$} \\
\hline & (1) & $(2)$ & $(3)$ & $(4)$ & $(5)$ & (6) \\
\hline Intercept & $\begin{array}{c}0.113 \\
(<0.001)\end{array}$ & $\begin{array}{c}0.276 \\
(0.014)\end{array}$ & $\begin{array}{c}0.616 \\
(<0.001)\end{array}$ & $\begin{array}{c}1.073 \\
(<0.001)\end{array}$ & $\begin{array}{c}0.573 \\
(<0.001)\end{array}$ & $\begin{array}{c}0.857 \\
(<0.001)\end{array}$ \\
\hline Market runup & $\begin{array}{l}0.101 \\
0.029\end{array}$ & $\begin{array}{l}0.120 \\
0.015\end{array}$ & $\begin{array}{c}0.924 \\
(<0.001)\end{array}$ & $\begin{array}{c}1.054 \\
(<0.001)\end{array}$ & $\begin{array}{c}0.933 \\
(<0.001)\end{array}$ & $\begin{array}{c}1.042 \\
(<0.001)\end{array}$ \\
\hline Whitened net runup & & & & & $\begin{array}{c}1.077 \\
(<0.001)\end{array}$ & $\begin{array}{c}1.068 \\
(<0.001)\end{array}$ \\
\hline \multicolumn{7}{|c|}{ Target characteristics } \\
\hline Target size & $\begin{array}{c}-0.015 \\
(<0.001)\end{array}$ & $\begin{array}{c}-0.012 \\
(<0.001)\end{array}$ & $\begin{array}{c}-0.054 \\
(<0.001)\end{array}$ & $\begin{array}{c}-0.048 \\
(<0.001)\end{array}$ & $\begin{array}{c}-0.039 \\
(<0.001)\end{array}$ & $\begin{array}{c}-0.035 \\
(<0.001)\end{array}$ \\
\hline NYSE/Amex & $\begin{array}{c}0.006 \\
(0.351)\end{array}$ & $\begin{array}{c}0.003 \\
(0.659)\end{array}$ & $\begin{array}{c}0.017 \\
(0.239)\end{array}$ & $\begin{array}{c}0.011 \\
(0.442)\end{array}$ & $\begin{array}{c}0.010 \\
(0.422)\end{array}$ & $\begin{array}{c}0.008 \\
(0.529)\end{array}$ \\
\hline Turnover & $\begin{array}{c}0.000 \\
(0.815)\end{array}$ & $\begin{array}{c}0.000 \\
(0.934)\end{array}$ & $\begin{array}{c}-0.001 \\
(0.561)\end{array}$ & $\begin{array}{c}0.000 \\
(0.775)\end{array}$ & $\begin{array}{c}0.001 \\
(0.589)\end{array}$ & $\begin{array}{c}0.000 \\
(0.698)\end{array}$ \\
\hline 52-week high & $\begin{array}{c}-0.042 \\
(<0.001)\end{array}$ & $\begin{array}{l}-0.027 \\
(0.026)\end{array}$ & $\begin{array}{c}-0.214 \\
(<0.001)\end{array}$ & $\begin{array}{c}-0.175 \\
(<0.001)\end{array}$ & $\begin{array}{c}-0.169 \\
(<0.001)\end{array}$ & $\begin{array}{c}-0.146 \\
(<0.001)\end{array}$ \\
\hline \multicolumn{7}{|c|}{ Bidder characteristics } \\
\hline Acquirer public & $\begin{array}{c}0.032 \\
(<0.001)\end{array}$ & $\begin{array}{c}0.032 \\
(<0.001)\end{array}$ & $\begin{array}{c}0.046 \\
(0.001)\end{array}$ & $\begin{array}{c}0.052 \\
(<0.001)\end{array}$ & $\begin{array}{c}0.012 \\
(0.305)\end{array}$ & $\begin{array}{c}0.018 \\
(0.136)\end{array}$ \\
\hline Horizontal & $\begin{array}{l}-0.015 \\
(0.036)\end{array}$ & $\begin{array}{l}-0.013 \\
(0.065)\end{array}$ & $\begin{array}{l}-0.009 \\
(0.536)\end{array}$ & $\begin{array}{l}-0.002 \\
(0.891)\end{array}$ & $\begin{array}{c}0.007 \\
(0.555)\end{array}$ & $\begin{array}{c}0.012 \\
(0.324)\end{array}$ \\
\hline Toehold size & $\begin{array}{l}-0.001 \\
(0.002)\end{array}$ & $\begin{array}{c}-0.002 \\
(<0.001)\end{array}$ & $\begin{array}{c}-0.003 \\
(<0.001)\end{array}$ & $\begin{array}{c}-0.004 \\
(<0.001)\end{array}$ & $\begin{array}{l}-0.002 \\
(0.014)\end{array}$ & $\begin{array}{r}-0.002 \\
(0.004)\end{array}$ \\
\hline Stake bidder & $\begin{array}{c}0.050 \\
(0.044)\end{array}$ & $\begin{array}{c}0.056 \\
(0.023)\end{array}$ & $\begin{array}{c}-0.029 \\
(0.560)\end{array}$ & $\begin{array}{l}-0.012 \\
(0.804)\end{array}$ & $\begin{array}{l}-0.082 \\
(0.051)\end{array}$ & $\begin{array}{r}-0.072 \\
(0.088)\end{array}$ \\
\hline Stake other & $\begin{array}{c}0.124 \\
(<0.001)\end{array}$ & $\begin{array}{c}0.125 \\
(<0.001)\end{array}$ & $\begin{array}{c}0.089 \\
(0.100)\end{array}$ & $\begin{array}{c}0.093 \\
(0.084)\end{array}$ & $\begin{array}{c}-0.044 \\
(0.340)\end{array}$ & $\begin{array}{r}-0.040 \\
(0.382)\end{array}$ \\
\hline \multicolumn{7}{|l|}{ Deal characteristics } \\
\hline Tender offer & $\begin{array}{c}0.037 \\
(<0.001)\end{array}$ & $\begin{array}{c}0.028 \\
(<0.001)\end{array}$ & $\begin{array}{c}0.094 \\
(<0.001)\end{array}$ & $\begin{array}{c}0.076 \\
(<0.001)\end{array}$ & $\begin{array}{c}0.055 \\
(<0.001)\end{array}$ & $\begin{array}{c}0.046 \\
(0.001)\end{array}$ \\
\hline All cash & $\begin{array}{l}-0.009 \\
(0.207)\end{array}$ & $\begin{array}{l}-0.001 \\
(0.919)\end{array}$ & $\begin{array}{l}-0.024 \\
(0.112)\end{array}$ & $\begin{array}{l}-0.002 \\
(0.914)\end{array}$ & $\begin{array}{c}-0.014 \\
(0.278)\end{array}$ & $\begin{array}{r}-0.001 \\
(0.949)\end{array}$ \\
\hline All stock & $\begin{array}{c}0.002 \\
(0.805)\end{array}$ & $\begin{array}{c}0.000 \\
(0.989)\end{array}$ & $\begin{array}{l}-0.005 \\
(0.755)\end{array}$ & $\begin{array}{l}-0.008 \\
(0.631)\end{array}$ & $\begin{array}{l}-0.007 \\
(0.600)\end{array}$ & $\begin{array}{r}-0.008 \\
(0.578)\end{array}$ \\
\hline Hostile & $\begin{array}{l}-0.009 \\
(0.503)\end{array}$ & $\begin{array}{l}-0.011 \\
(0.423)\end{array}$ & $\begin{array}{l}-0.005 \\
(0.865)\end{array}$ & $\begin{array}{l}-0.008 \\
(0.773)\end{array}$ & $\begin{array}{c}0.005 \\
(0.825)\end{array}$ & $\begin{array}{c}0.004 \\
(0.874)\end{array}$ \\
\hline Year fixed effects & no & yes & no & yes & no & yes \\
\hline Adjusted- $R^{2}$ & 0.026 & 0.039 & 0.077 & 0.092 & 0.339 & 0.346 \\
\hline F-value & 12.5 & 6.85 & 37.4 & 15.7 & 209.2 & 76.0 \\
\hline
\end{tabular}




\section{about ECGI}

The European Corporate Governance Institute has been established to improve corporate governance through fostering independent scientific research and related activities.

The ECGI produces and disseminates high quality research while remaining close to the concerns and interests of corporate, financial and public policy makers. It draws on the expertise of scholars from numerous countries and bring together a critical mass of expertise and interest to bear on this important subject.

The views expressed in this working paper are those of the authors, not those of the ECGI or its members. 


\section{ECGI Working Paper Series in Finance}

Editorial Board

Editor

Consulting Editors

Editorial Assistants :
Ernst Maug, Professor of Corporate Finance, University of Mannheim, ECGI

Franklin Allen, Nippon Life Professor of Finance and

Economics, The Wharton School, University of

Pennsylvania, ECGI

Julian Franks, Professor of Finance, London Business School, $\mathrm{ECGI}$ and CEPR

Marco Pagano, Professor of Economics, Università di Napoli Federico II, ECGI and CEPR

Xavier Vives, Professor of Economics and Financial Management, IESE Business School, University of Navarra, ECGI and CEPR

Luigi Zingales, Robert C. McCormack Professor of

Entrepreneurship and Finance, University of Chicago, Booth School of Business, ECGI and CEPR

Pascal Busch, University of Mannheim

Marcel Mager, University of Mannheim

Florian Protschky, University of Mannheim 


\section{Electronic Access to the Working Paper Series}

The full set of ECGI working papers can be accessed through the Institute's Web-site (www.ecgi.org/wp) or SSRN:

Finance Paper Series http://www.ssrn.com/link/ECGI-Finance.html

Law Paper Series http://www.ssrn.com/link/ECGI-Law.html 